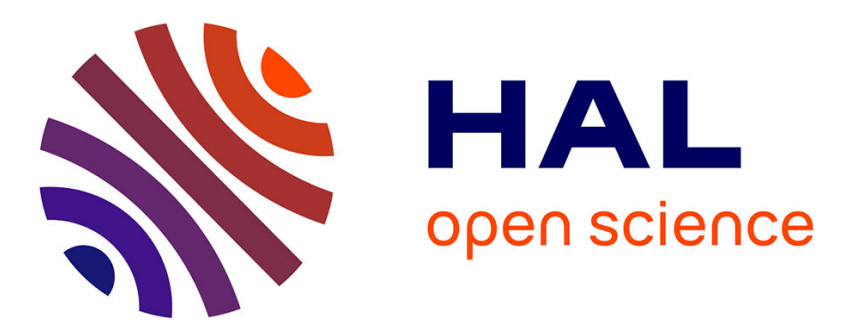

\title{
Consumer Responses to Corporate Social Responsibility (CSR) Contribution Type
}

\author{
Diogo Hildebrand, Yoshiko Demotta, Sankar Sen, Ana Valenzuela
}

\section{To cite this version:}

Diogo Hildebrand, Yoshiko Demotta, Sankar Sen, Ana Valenzuela. Consumer Responses to Corporate Social Responsibility (CSR) Contribution Type. Journal of Consumer Research, 2017, 10.1093/jcr/ucx063 . hal-01576949

\section{HAL Id: hal-01576949 \\ http://hal.grenoble-em.com/hal-01576949}

Submitted on 24 Aug 2017

HAL is a multi-disciplinary open access archive for the deposit and dissemination of scientific research documents, whether they are published or not. The documents may come from teaching and research institutions in France or abroad, or from public or private research centers.
L'archive ouverte pluridisciplinaire HAL, est destinée au dépôt et à la diffusion de documents scientifiques de niveau recherche, publiés ou non, émanant des établissements d'enseignement et de recherche français ou étrangers, des laboratoires publics ou privés. 
Original citation: Hildebrand, Diogo, Yoshiko DeMotta, Sankar Sen, Ana Valenzuela (2017). Consumer Responses to Corporate Social Responsibility (CSR) Contribution Type. Journal of Consumer Research, doi: 10.1093/jcr/ucx063

\title{
Consumer Responses to Corporate Social Responsibility (CSR) Contribution Type
}

\author{
DIOGO HILDEBRAND \\ YOSHIKO DEMOTTA \\ SANKAR SEN \\ ANA VALENZUELA
}

This article has been accepted for publication at the Journal of Consumer Research.

Link to the original publication: https://academic.oup.com/jcr/articleabstract/doi/10.1093/jcr/ucx063/3739797/Consumer-Responses-to-CorporateSocial?redirectedFrom=fulltext 


\begin{abstract}
AUTOR NOTE
Diogo Hildebrand (diogo.hildebrand@grenoble-em.com) is assistant professor of marketing, Grenoble Ecole de Management, 12 Rue Pierre Semard, 38000, Grenoble, France, Tel: + 33 (0)456 806676. Yoshiko DeMotta (ydemotta@fdu.edu) is assistant professor of marketing, Fairleigh Dickinson University, 285 Madison Avenue, Madison, NJ 07940. Sankar Sen (sankar.sen@baruch.cuny.edu) is Lawrence and Carol Zicklin Professor of Corporate Integrity and Governance, Baruch College (CUNY), 55 Lexington Ave, New York, NY 10010. Ana Valenzuela (ana.valenzuela@baruch.cuny.edu) is professor of marketing, Baruch College (CUNY), and ESADE Business School, Ramon Llull University, Av. de Pedralbes, 60-62, 08034 Barcelona, Spain. Correspondence: Diogo Hildebrand. Supplementary materials are available in the web appendix in the online version of the article. The authors thank the editor, associate editor, and reviewers for their helpful comments. The first and second authors contributed equally to the manuscript, and authorship order was determined by a coin flip.
\end{abstract}




\begin{abstract}
While companies contribute in different ways to the corporate social responsibility (CSR) issues they support, little is known about the effects of varying CSR contribution types on consumers' evaluations of the contributing company. This paper examines consumer reactions to two basic contribution types - money versus in-kind - in the CSR domain of disaster relief to demonstrate, through five studies, that while consumers evaluate a company more favorably when it makes in-kind rather than monetary contributions of equivalent value to CSR issues that are perceived to be less controllable, the pattern reverses when the company's contributions are made to CSR issues that are perceived to be more controllable. This interaction between contribution type and perceived issue controllability is more likely to manifest when controllability is accessible in the minds of consumers. The underlying process is driven by the extent to which the disparate emotionality of each contribution type matches the intensity of felt emotion evoked by CSR issues of varying perceived controllability, producing processing fluency.
\end{abstract}

Keywords: corporate social responsibility, contribution type, controllability, emotion, fluency 
Companies today dedicate considerable resources to alleviate the ills of the world (e.g., illness, pollution, poverty, disasters). Much research (Ellen, Webb, and Mohr 2006; Gupta and Pirsch 2006; Nan and Heo 2007; Pracejus and Olsen 2004; Sen and Bhattacharya 2001) points to the shared value created by such corporate social responsibility (CSR) initiatives: these corporate actions not only help make the world a better place but also garner positive reactions from consumers, helping build or burnish a company's reputation. Importantly, in articulating their CSR strategy, companies need to decide not only which issues to support and how much to contribute but also in what ways (e.g., cash, products, company know-how, employee volunteerism). Yet, while the burgeoning research on consumer reactions to CSR (see Sen, Du, and Bhattacharya 2016 for recent review) documents the moderating roles of a variety of company-specific (e.g., CSR-company fit; company involvement; brand positioning and firm reputation) and CSR-specific (e.g. perceived motives; perceived efficacy) factors, insights into whether and how different types of corporate contributions (e.g., money versus in-kind) to social and environmental issues influence consumers' evaluations of the company remain scarce (cf. Ellen, Mohr, and Webb 2000).

A case in point is disaster relief. From forest fires to tsunamis, from Katrina to Sandy, companies have devoted billions of dollars, both in cash and kind, to disaster relief in just the last decade (U.S. Chamber of Commerce 2011). The Japanese earthquake and tsunami in March 2011, for instance, elicited over $\$ 300$ million in corporate aid. Interestingly, the logistics services company FedEx donated one million dollars (mostly cash), while its rival UPS provided transportation and logistics expertise (U.S. Chamber of Commerce 2011). Might consumers' evaluations of these two rivals be different? If so, how and why? As well, not all disasters, and more generally, the CSR issues eliciting company support are the same; might consumers' 
contribution type-based company evaluations be shaped by certain characteristics of the issues themselves?

This paper examines consumer reactions to two basic contribution types - money versus in-kind - in the CSR domain of disaster relief. It theorizes that consumers' evaluations of a company hinge not just on the type of contribution but rather on the match between the extent to which a contribution type is associated with emotional concepts (i.e., the emotionality of the contribution type) and the intensity of the felt emotion (i.e., emotional intensity) elicited by issues of varying perceived controllability (e.g., disease, poverty, disaster). Five experiments provide both support for this basic assertion and evidence for the process theorized to underlie it. Specifically, we demonstrate that consumers evaluate a company more favorably when it makes in-kind rather than monetary contributions of equivalent value to issues that are perceived to be less controllable. However, they evaluate a company more favorably when it makes monetary rather than in-kind contributions of equivalent value to issues that are perceived to be more controllable. Notably, because this interaction hinges on the perceived controllability of the CSR issue, we find, as theorized, that it is more likely to manifest when the notion of controllability is more accessible in the minds of consumers, as is often the case in the contexts (e.g., media reports) in which consumers learn about CSR issues (Dou and Wong 2015; Geeta 2016; Huffington Post 2013; Kolata 2010). Finally, we locate this interaction in the greater match between the higher emotional intensity elicited by uncontrollable issues and the higher emotionality of in-kind contributions on the one hand, and between the lower emotional intensity elicited by controllable issues and the lower emotionality of monetary contributions on the other. This emotion-based match, in turn, allows consumers to process the contribution information more fluently, producing perceptions of greater fit between the contribution and the CSR 
issue/cause (i.e., contribution-cause fit) and, importantly, more positive company evaluations.

This research makes three contributions. First, it advances our conceptual understanding of consumer reactions to CSR by painting a nuanced picture of how contribution type interacts with a key dimension of the contribution-eliciting issue to shape consumers' company evaluations. In doing so, this research goes beyond the general dominance, in terms of consumer preferences, of in-kind over monetary contributions suggested by Ellen et al. (2000) to establish its consumer- and CSR issue-contingent nature. Second, it provides evidence for the underlying process, implicating the experience of fluency borne of the emotion-based match between issue controllability perceptions and the different contribution types as a driver of company evaluations. In doing so, this research contributes to the more recent strand of CSR research (Kim and Johnson 2013; Peloza, White and Shang 2013) aimed at uncovering the affective mechanisms underlying consumer reactions to CSR. Third, and more specifically, it broadens our extant understanding of fit, a notion central to the CSR literature (Gupta and Pirsch 2006; Nan and Heo 2007; Pracejus and Olsen 2004), by introducing a new fluency-based conceptualization that is particularly germane to consumer judgments of companies' contributions to not just disaster relief but any CSR issues wherein controllability perceptions of the focal issue loom large.

\section{THEORETICAL FRAMEWORK}

Monetary versus In-kind Contributions 
Differences in consumers' reactions to monetary versus in-kind corporate contributions are likely to hinge on certain dimensions on which these contribution types vary. One such dimension is their level of emotionality, which we define as the extent to which each contribution type is associated with emotional concepts (Kim et al. 2015; Nielsen, Shapiro, and Mason 2010; Ochser and Gross 2007). We suggest that in-kind contributions are likely to be characterized by greater emotionality than are monetary contributions. Primary support for this assertion comes from a growing body of research (Liu and Aaker 2008; Pfeffer and DeVoe 2009; Quoidbach et al. 2010; Vohs, Mead, and Goode 2006) that points to consumers' emotional associations with inkind (e.g., time) resources, as opposed to their more rational, economic value-related associations with monetary resources. Most germane, Liu and Aaker (2008) suggest, in the context of charitable giving, that solicitations of in-kind contributions, such as that of volunteering time, trigger more emotional meanings because time, particularly its consumption, is associated with inherently emotional experiences (Schwarz and Clore 1996; Van Boven and Gilovich 2003) as well as goals with emotional meaning (Liu and Aaker 2008). Solicitations of money, on the other hand, trigger less emotional associations tied to economic exchange and, concomitantly, value calculation and maximization (Vohs et al. 2006).

The notion that in-kind donations are of greater emotionality is echoed, more generally, in research on altruism and gift giving. For instance, in-kind donations (e.g., nicotine patches, as opposed to cash) are associated with greater empathy (Jacobsson, Johannesson, and Borquist 2007) and believed to confer social approval, prestige, and respect to the giver (Ellingsen and Johannesson 2011), all concepts with significant emotional content. It is not surprising, then, that in-kind contributions are more likely from donors with higher social capital (Bin and Edwards 2009). Relatedly, Reed, Aquino and Levy (2007) establish a positive link between the importance 
to consumers of their moral identity - again, an intrinsically emotional construct (see Reed et al. 2007, p.191) - and their preference for donating time over money due to the former's greater perceived morality and self-expressiveness.

Finally, several threads of research on the gifting of money versus in-kind gifts coalesce around the sense, at least among gifters, of the greater thoughtfulness (Gino and Flynn 2011) or, more generally, psychic costs (Robben and Verhallen 1994), of in-kind gifts. In particular, some gift-giving research (Pieters and Robben 1999; Webley, Lea, and Portalska 1983) points to the perceived unacceptability of monetary gifts within self-relevant, inherently emotional relationships (e.g., mother-child) because these convey a lack of effort on the part of the gifter. This is consistent with research in a broader set of domains (e.g., Morales 2005) pointing to the greater emotionality of more effortful actions. Interestingly, research (Ellen et al. 2000) contrasting a company's collection of products versus cash from its consumers for the purpose of disaster relief finds that these consumers ascribe greater effort to the former than to the latter. If a company's own in-kind contributions are seen, similarly, as more effortful than its cash contributions, then this difference is also likely to contribute to the greater emotionality of in-kind contributions over cash.

Next, we focus on a key dimension of the issue eliciting corporate contributions - its perceived controllability - that is likely to interact with the varying emotionality of the monetary versus in-kind contributions to affect consumer reactions to the company.

Perceived Issue Controllability 
The CSR issues that garner support from companies vary in the extent to which their causes are perceived by consumers to be controllable by some human agent or agents, as opposed to nature or happenstance (Lerner 1980; Schul et al. 2007; Weiner 1980). For instance, issues such as climate change and the AIDS crisis are deemed by most to be largely controllable, whereas breast cancer, Alzheimer, and other genetic diseases are perceived as more uncontrollable (Kolata 2010; Huffington Post 2013; Weiner, Perry, and Magnusson 1988). In the context of disasters, consumers perceived the 2010 Haiti earthquake as largely uncontrollable (Geeta 2016) whereas the 2015 landslide in Shenzhen, China, was perceived to be more controllable (Dou and Wong 2015).

We assert that the perceived controllability of a CSR issue determines the intensity of consumers' emotional reaction to it, influencing, in turn, their reactions to the type of contribution (i.e., monetary vs. in-kind) made by a company. Why might this be so? A broad body of research (Alicke 2000; Bohner et al. 1988; Lerner 1980; Weiner 1980) suggests that consumers typically react in an emotionally intense manner to the negative, often unexpected, event at the heart of most if not all CSR issues, spurring them to repair this aversive, threatening emotional state by making sense of the event, often quickly and automatically (Wilson and Gilbert 2003; Weiner, Osborne, and Rudolph 2011). A crucial step in this sense-making process is centered on consumers' appraisals of the extent to which any such event is controllable by human agents (Alicke 2000).

Controllability appraisals allow consumers to assess whether or not the event was intentional, predictable and, if necessary, preventable, reducing the uncertainty connected to the event itself as well as their own ability to deal with it should such an event befall them (Alicke 2000; Bohner et al. 1988; Lerner 1980; Weiner 1980). In fact, ascriptions of controllability to a 
human agent(s) contribute to what Wilson and Gilbert (2003) refer to as an "ordinization" of the event. Such "ordinization" renders the event more explainable and understandable, turning the extraordinary into ordinary and reducing, consequently its emotional power and the intensity of consumers' emotional reactions to it. This negative relationship between perceived controllability and the intensity of felt emotion is underscored by more recent neuropsychological research (Carlsson et al. 2006; Maier 2105), which documents the link between greater controllability assessments and a lower activation of affective neural processing of aversive, painful stimuli.

It is worth noting that the effect of controllability perceptions on the emotional intensity of one's reactions are pervasive, affecting the reactions of both victims and onlookers, regardless of the precise locus of control (i.e., the onlooker; the victims; a third party). This notion is supported by research both neuropsychological (Buchanan et al. 2011; Carlsson et al. 2006; Maier 2015) and motivational (Bar-Anan, Wilson, and Gilbert 2009; Burger and Arkin 1980) showing that the intensity of people's affective responses to a misfortune, whether their own or another's, diminishes with heightened perceptions of the misfortune's controllability, regardless of how controllable it actually is.

Next, we theorize about how a company's CSR contribution type might interact with consumers' perceived controllability of the CSR issue to affect their company evaluations.

Fluency, Fit and Company Evaluation

Central to our conceptualization of consumers' contingent responses to CSR contribution type is the assertion that the relatively lower intensity of felt emotion induced by CSR issues 
perceived to be largely controllable will cause consumers to process a company's monetary contribution, characterized by lower emotionality, more fluently than its higher emotionality, inkind counterpart. Conversely, the higher intensity of felt emotion induced by uncontrollable CSR issues will cause the higher emotionality in-kind contributions to be processed more fluently. Support for this notion comes from research (Halberstadt and Niedenthal 1997; Hsee and Rothenstreich 2004; Lai, Hagoort, and Casasanto 2012) that contrasts, in diverse settings, consumers in an emotional state (i.e., higher intensity of felt emotion) to those in a deliberative state (i.e., lower intensity, if any, of felt emotion) to show that while the former are more likely to attend to subsequent information that is higher in emotionality, the latter are more likely to attend to information lower in emotionality. This process is guided, at least in part, by the preferential activation of emotional intensity-consistent concepts in memory (Lai et al. 2012; Levine and Ramirez 2013; Niedenthal, Halberstadt and Innes-Ker 1999) and, in the case of emotional information, not necessarily restricted to specific emotion types (Brosch, Pourtois and Sander 2010; Lai et al. 2012; Levine and Ramirez 2013; Niedenthal et al. 1999). The increased attention to emotional intensity-consistent information is likely to result, in turn, on a greater speed and ease of its processing (Dweck, Mangels and Good 2004; Lai et al. 2012), producing a subjective experience of processing ease, or fluency (Alter and Oppenheimer 2009; Topolinski and Strack 2008, 2009).

Extant research (for a summary see Alter and Oppenheimer 2009, p. 228) points to the positive affect produced by the experience of fluency as a key determinant of consumers' favorable evaluations of fluently processed information. Given that consumer evaluations of the contribution type undertaken by a company are likely to spillover to the contributing company itself (Yoon, Gürhan-Canli, and Schwartz 2006), we expect more fluently processed contribution- 
type information to produce more positive company evaluations. Additionally, a related but distinct body of work (Topolinski and Strack 2009) points to the possibility that feelings of fluency may produce an almost intuitive hunch that the fluency-producing items of information fit together well (i.e., they are coherent and make sense together). Notably, research, much of it in the domain of CSR itself (see Sen et al. 2016 for recent review), suggests that a similar sense of fit or match between a CSR issue and a company's actions towards it can also produce greater liking for the company. In sum, then, we expect both a direct effect of processing fluency as well as an indirect effect through perceptions of contribution-cause fit to cause consumers to evaluate a company more positively when it makes in-kind contributions, as opposed to monetary contributions, to a CSR issue that is perceived to be relatively uncontrollable. When a CSR issue is perceived as relatively controllable, however, these direct and indirect effects of fluency should cause consumers to evaluate a company more positively when it makes monetary contributions rather than in-kind contributions.

The Moderating Role of Controllability Accessibility

If consumers' reactions to CSR contribution type hinge, as implied by our conceptualization, on their perceived controllability of the CSR issue, then the predicted interactive effects of contribution type and perceived issue controllability on fluency, fit and evaluation should be more pronounced when the notion of controllability is more accessible to consumers (Bhatia 2013; Taylor and Fiske 1978; Sherman, Mackie, and Driscoll 1990; Smith et al. 1993). A vast body of work points to the accessibility, construed broadly to subsume "notions of salience for externally provided stimuli and retrievability and activation strength for memories 
and other mental objects (Bhatia 2013, p.524)" of an evaluative input or dimension (such as controllability) as a key driver of its influence on relevant judgments (Bhatia 2013; Cervone et al. 2008; Higgins 1996; Sherman et al. 1990). This is because dimensions that are more accessible receive greater attention and have a greater chance of being sampled and weighted in subsequent judgments (Bhatia 2013; Cervone et al. 2008; Higgins 1996; Schwartz and Strack 1981; Sherman et al. 1990).

Accessibility is often a function of the extent to which that dimension has been used in recent judgments (Förster and Liberman 2007; Mussweiler and Damisch 2008; Smith and Brascombe 1987) or presented repeatedly to the consumer (Feldman and Lynch 1988; Lu, Xie, and Liu 2015). At the same time, recurrent use of an evaluative dimension can render that dimension chronically accessible. For instance, Burger and Hemans (1988) observed that controllability, and attributions thereof, are chronically accessible for those who are high in their general desire for control in that they not only make more controllability-related queries but are also more likely to use controllability-related information in relevant judgments. In other words, consumers with a chronic desire for control tend to constantly appraise life events in terms of their controllability, causing this evaluative dimension to, over time, become chronically accessible (Förster and Liberman 2007; Higgins 1996; Smith et al. 1993).

Based on this, we propose that when the notion of controllability is either contextually or chronically accessible, consumers will be more likely to focus on the controllability of the CSR issue. This heightened focus is likely to polarize, relative to when controllability is less accessible, consumers' controllability perceptions of high versus low controllability CSR issues, polarizing, in turn, the intensity of their emotional reaction to CSR issues of varying controllability (Cervone et al. 2008; Higgins 1996; Smith et al. 1993). As a result, high (versus 
low) controllability accessibility consumers are more likely to experience fluency, or the lack thereof, during the processing of CSR contribution type information, driving their perceptions of contribution-cause fit and company evaluation.

Overview of Studies

Next, we report five studies that test our framework of consumer reactions to corporate contributions (figure 1) in the CSR context of disaster relief. Study 1 tests our basic outcome prediction. Study 2 provides support for our foundational assertions regarding the higher intensity of felt emotions elicited by CSR issues that are perceived to be uncontrollable as opposed to controllable (study 2A) and the greater emotionality of in-kind over monetary contribution type (study 2B). Study 3 explicitly tests for the role of controllability-induced emotional intensity by showing its influence on their evaluations of companies making monetary and in-kind contributions. Finally, study 4 provides evidence, through both moderation and mediation, for our fluency-based account while ruling out certain key alternative accounts. Importantly, in all studies we followed standard procedures (e.g., Baskin et al. 2014; Shapiro 1999) to exclude participants who skipped the experimental manipulations, failed attention check questions that asked what condition they were in, were suspicious about study objectives, and/or explicitly reported difficulties in understanding the instructions and experimental materials.

Insert Figure 1 about here 
The main objective of this study was to test our basic prediction that consumers will evaluate a company making monetary contributions, rather than in-kind contributions, to a CSR issue more favorably when that issue is perceived to be largely controllable but less favorably when that issue is perceived to be largely uncontrollable. We also aim to show that this interaction is more likely in contexts wherein the notion of controllability is accessible. Finally, we test for the validity of our conceptualization of perceived controllability as one driven, more generally, by some human agent(s) rather than just specific entities, such as the victims (Schul et al. 2007; Weiner et al. 1988).

\section{Design and Procedure}

We recruited 216 participants through the Amazon Mechanical Turk platform in exchange for a fee. Two participants were excluded based on our screening criteria described earlier, resulting in a total of 214 participants $(52.3 \%$ female; average age $=37.4)$. We employed a 2 (Contribution Type: monetary vs. in-kind) $\times 2$ (Issue Controllability: high vs. low) $\times 2$ (Controllability Accessibility: high vs. low) between-subjects design, with company evaluation as the dependent variable. We first primed controllability accessibility using a procedural priming task (adapted from Harris, Griffin and Murray 2008), wherein repeated judgments involving a dimension (e.g., controllability) increase its likelihood of being used, unprompted, in subsequent judgments (Mussweiler and Damisch 2008; Smith and Brascombe 1987). Accordingly, in the high controllability accessibility condition, we asked participants to read 15 short descriptions of daily events (e.g., being late for work, developing a stomach ache, receiving a complement) and indicate, for each, the extent to which they felt they had control over its occurrence $(1=$ not at all 
controllable, 7 = completely controllable). In the low accessibility condition, we asked participants to read the same 15 event descriptions and indicate the frequency with which each happens to them $(1=$ never, $7=$ very frequently $)$. Aside from serving as a control condition, we expected respondents' increased focus on frequency to even inhibit the accessibility of controllability-related thoughts (Förster and Liberman 2007; Sherman et al. 1990).

Participants then read two fictitious news reports that systematically manipulated perceived issue controllability and corporate contribution type (see the web appendix for study stimuli). The first report manipulated issue controllability, based on research linking the cause of a disaster, either manmade or natural, to its perceived controllability (Baum and Fleming 1993; Zagefka et al. 2011), by describing an avalanche in California in 2008 as caused either by snowmobiles (i.e., a manmade disaster: high issue controllability condition) or a snowstorm (i.e., a natural disaster: low issue controllability condition). An online pretest $(\mathrm{N}=110)$ verified the effectiveness of the controllability accessibility and issue controllability manipulations. The pretest used a 2 (Controllability Accessibility: high vs. low) $\times 2$ (Issue Controllability: high vs. low) between-subjects design. After performing the controllability accessibility manipulation and reading the news report about the disaster, participants of the pretest indicated their level of agreement (7-point scale; $1=$ strongly disagree, 7 = strongly agree) with the statements "The disaster was preventable", "Someone had the capability to stop the disaster from occurring", "The affected community is to be blamed for the disaster", and "The affected community is responsible for the disaster". The first two items were averaged to form the Issue Controllability manipulation check $(r=.93, p<.001)$ and the latter two items were averaged to check the potential role of Victim Responsibility $(r=.83, p<.001)$. An ANOVA with Controllability Accessibility and Issue Controllability as independent variables revealed a significant main effect of Issue 
Controllability on the manipulation check $\left(M_{\text {high }}=4.83, M_{\text {low }}=2.36, \mathrm{~F}(1,106)=67.35, p<\right.$ $.001)$ and, as theorized, a significant Issue Controllability $\times$ Controllability Accessibility interaction $(\mathrm{F}(1,106)=8.00, p<.01)$. Planned contrasts revealed that the effect of Issue Controllability was significantly stronger in the high Controllability Accessibility condition $\left(\mathrm{F}(1,107)=66.51, p<.001, \eta_{\mathrm{p}}^{2}=.38\right)$ than in the low Controllability Accessibility condition $\left(\mathrm{F}(1,107)=12.33, p<.01, \eta^{2}=.10\right)$. We also found, in line with prior research (Lerner 1980; Zagefka et al. 2011), a significant main effect of Issue Controllability on perceived Victim Responsibility $\left(M_{\mathrm{high}}=2.21, M_{\mathrm{low}}=1.83, \mathrm{~F}(1,106)=4.34, p<.05, \eta_{\mathrm{p}}^{2}=.04\right)$. Importantly, the role of Victim Responsibility was, in and of itself, negligible, in terms of both the means as well as the effect size, compared to attributions of controllability to, more broadly, some human agent(s) (i.e., manipulation check; $\eta_{\mathrm{p}}^{2}=.39$; Perdue and Summers 1986).

After reading the avalanche news report, participants read a second news report that described a company's disaster relief initiative. Specifically, the article reported that in response to the avalanche, a computer technology services company had decided to either donate one million dollars, which would be used for the procurement and allocation of food and medicines to affected communities (i.e., monetary contribution condition), or provide employee volunteers and services to help with the procurement and allocation of food and medicines, an effort that would cost the company one million dollars (i.e., in-kind contribution condition). We made donation usage and cost equivalent across the two contribution type conditions to control for potentially confounding variations in respondents' perceptions of company involvement. Regardless, we expect, in line with the findings of Liu and Aaker (2008), that the theorized differences in emotionality will be produced by the mere mention of each of the two contribution types (a more direct test of this premise follows in study 2B). 
Next, participants evaluated the company using a four-item seven-point scale $(1=$ not at all favorable; very bad; not at all appealing; not at all helpful; 7 = very favorable; very good; very appealing; very helpful). We averaged these to obtain an overall measure of company evaluation $(\alpha=.94)$. Participants then indicated their gender and age.

Results and Discussion

Company Evaluation. To test our outcome prediction, we conducted an ANOVA with Contribution Type, Issue Controllability, and Controllability Accessibility as independent variables, and Company Evaluation as the dependent variable. Both the main effect of Controllability Accessibility $(F(1,206)=4.02, p<.05)$, and the interaction between Contribution Type and Issue Controllability $(F(1,206)=3.65, p=.06)$ were significant, the latter albeit marginally so. More importantly, consistent with our prediction, we found a significant three-way interaction $(F(1,206)=4.80, p<.05)$. Planned contrast analyses revealed a significant two-way interaction between Contribution Type and Issue Controllability in the high Controllability Accessibility condition $(F(1,211)=9.25, p<.01)$. As illustrated in Figure 2, participants evaluated the company more positively when it contributed money (vs. services) as relief towards the controllable disaster $\left(M_{\text {monetary }}=6.60, M_{\text {in-kind }}=6.06, F(1,209)=4.88, p<.05\right)$ but contributed services (vs. money) as relief towards the uncontrollable disaster $\left(M_{\text {monetary }}=\right.$ $\left.5.92, M_{\text {in-kind }}=6.45, F(1,209)=4.41, p<.05\right)$. In the low accessibility condition, on the other hand, the two-way interaction was not significant $(F(1,211)=.05, p>.10)$ : Contribution Type and Issue Controllability did not affect company evaluations $\left(M_{\text {high controllability-monetary }}=6.08, M_{\text {high }}\right.$ 
controllability-in-kind $=5.82, F(1,209)=1.34, p>.10 ; M_{\text {low controllability-monetary }}=6.20, M_{\text {low controllability- }}$

in-kind $=5.87, F(1,209)=1.86, p>.10)$.

Insert Figure 2 about here

A follow-up lab study with 125 participants, not reported in full for the sake of brevity (data available upon request), obtained an identical pattern of results using a measure of chronic rather than task-triggered Controllability Accessibility. Specifically, we operationalized controllability accessibility through the Desirability of Control (DC) scale (Burger and Cooper 1979; see study 2A for measure details), premised on the higher accessibility of controllability among participants with a greater desire for control (Burger and Hemans 1988; Thompson and Schlehofer 2008). As expected, the regression analysis revealed a significant three-way interaction $(\mathrm{t}(117)=3.04, \mathrm{p}<.01)$. Simple slopes analyses indicated that participants high in DC (+1 SD) evaluated the company more positively when it contributed money (vs. services) to help the victims of the controllable disaster $(\mathrm{t}(117)=2.00, \mathrm{p}<.05)$, and when it contributed services (vs. money) to help the victims of the uncontrollable disaster $(\mathrm{t}(117)=-2.33, \mathrm{p}<.05)$. There were no significant differences for the participants low in DC (-1 SD) ( $p$ 's > .10).

Our basic outcome prediction hinges on the two, independent premises of (a) the greater emotionality of in-kind, relative to monetary, contributions and (b) consumers' more intense emotional reactions to CSR issues they perceive to be less controllable. We aim to provide support for each of these premises, individually, in the next two studies, $2 \mathrm{~A}$ and $2 \mathrm{~B}$, using the standard response latency (i.e., reaction time) paradigm (Lai et al. 2012; Topolinski and Strack 2009). Specifically, we expect the relative speed with which participants identify more emotional, 
as opposed to less emotional concepts, to be greater when they are exposed to less controllable, as opposed to more controllable, CSR issues (study 2A) and in-kind, as opposed to monetary, contributions (study 2B). Notably, we decided to use this indirect procedure to reduce concern with social desirability (Quirin, Kazén, and Kuhl 2009), which could influence more direct assessments of consumers' emotional reactions to disasters and aid provided its victims.

\section{STUDY 2A}

This study tests for the greater emotional intensity characterizing consumers' reactions to less controllable CSR issues by examining their reaction times to more emotional versus less emotional concepts. We expect, based on research linking stimuli evoking a greater intensity of felt emotion to the activation and consequent accessibility of more emotional concepts in memory (Brosch et al. 2010; Lai et al. 2012), that the relative speed with which participants identify more emotional versus less emotional concepts will be greater after their exposure to an uncontrollable CSR issue relative to a more controllable one.

\section{Design and Procedure}

A total of 142 undergraduate students participated in this study for partial course credit. We examined the perceived CSR issue controllability-based differences in participants' reaction times to more emotional versus less emotional concepts using a one factor (Issue Controllability: high vs. low) between-subjects design, with a measure of chronic controllability accessibility (i.e., Desirability of Control or DC) as the moderator. In line with our theorizing, the perceived CSR issue controllability-based difference in participants' reaction times should be greater for 
those higher in DC (Burger and Hemans 1988; Thompson and Schlehofer 2008). The scenario used to manipulate perceived issue controllability was identical to that in study 1 .

Participants first read the article about an avalanche in California. In line with this study's objective, participants were not exposed to the article containing the contribution type manipulation. We assessed the accessibility of more and less emotional concepts by measuring participants reaction time to four words: "emotional" and "feeling" (i.e., more emotional), and "rationality" and "analytical" (i.e., less emotional). Although response time to a single word can suffice as a measure of concept activation (Wilcox et al. 2009), we decided to use four words to increase the reliability of the measure (see Chatterjee, Irmak, and Rose (2013) for a similar procedure). In line with prior research (Chatterjee et al. 2013) we created an emotion index by subtracting the reaction times (RT) for the two more emotional words from that for the two less emotional words (analyses using just the more emotional words yielded comparable results). Given that a faster reaction time to a word points to greater accessibility of the corresponding concept in participants' minds (Collins and Loftus 1975; Topolinski and Strack 2008), higher values of the emotion index (i.e., $\mathrm{RT}_{\text {low emotion }}-\mathrm{RT}_{\text {high emotion }}$ ) reflect higher accessibility of more emotional concepts and lower accessibility of less emotional concepts (Brosch et al. 2010; Lai et al. 2012).

We used the MediaLab and DirectRT software to present the instructions and collect response time measures. Specifically, the computer screen presented participants with a series of trials in which a fixation point $(++++)$ would be followed by a string of letters. Participants were told that the string of letters could be a word (e.g., vacation) or a non-word (e.g., favan, niare), and were instructed to identify each word on the screen, thus, by pressing a specific letter on the keyboard (i.e., "W" for a word and "N" for a non-word). They were also instructed to give equal 
importance to both accuracy and speed in this identification task. After practicing with 10 trials, participants were exposed to 54 strings of letters (27 words, 27 non-words), among which the focal words were randomly presented. Finally, after a filler task, we assessed participants' controllability accessibility using the DC scale (Burger and Cooper 1979).

Results and Discussion

Thirteen participants were eliminated based on our general screening criteria. Following convention in response latency studies (Fazio 1990), we further excluded from analyses fifteen participants who identified at least one focal word incorrectly and two whose reaction time to the focal words exceeded three standard deviations from the mean, rendering a final sample of 112 participants $(52.1 \%$ female; average age $=22)$. We then created a DC index, excluding, in line with prior research (McCutcheon 2000), items with low item-total correlation. The final 10 items were averaged to obtain each participant's DC index score $(\alpha=.86$; see web appendix for scale items).

Following extant research (Lakens 2011; Lo and Andrews 2015), we analyzed the emotion index using a Generalized Linear Model with gamma distribution and log link. We also analyzed the data using the more common linear regression and found virtually identical results. To test our hypothesis, we included Issue Controllability, Controllability Accessibility (i.e., DC index) and their interaction as predictors of the emotion index; we added a small constant to the index to guarantee positive scores, a requirement of gamma distributions (the reported means are untransformed to improve interpretability). Results showed a significant main effect of Issue Controllability $\left(\beta=.17, \chi^{2}=9.68, p<.01\right)$ and, importantly, a significant interaction between 
Issue Controllability and Controllability Accessibility $\left(\beta=.23, \chi^{2}=6.80, p<.01\right)$. As predicted, simple effects analyses revealed that participants high in Controllability Accessibility (+1 SD in the DC index) presented higher emotion index scores in the uncontrollable disaster condition than in the controllable one $\left(M_{\text {Low Controllability }}=-15, M_{\text {High Controllability }}=311, \chi^{2}=14.36, p\right.$ $<.001)$. Participants low in Controllability Accessibility (-1 SD in the DC index), on the other hand, were no different in their emotion index scores across the two Issue Controllability conditions $\left(M_{\text {Low Controllability }}=138, M_{\text {High Controllability }}=121, \chi^{2}=.04, p>.10\right)$.

In summary, this study shows that, as theorized, the perceived controllability of a CSR issue affects the intensity of consumers' emotional reaction: relative to less emotional concepts, more emotional concepts were more accessible to participants reacting to a CSR issue they perceived to be less controllable. As well, in line with our theorizing, this association was stronger for participants with chronically higher, as opposed to lower, levels of controllability accessibility.

\section{STUDY 2B}

This study tests for the greater emotionality of in-kind, relative to monetary, contributions by examining their reaction times to more emotional versus less emotional concepts. Similar to the increased accessibility caused by the intensity of an individual's emotional state observed in study $2 \mathrm{~A}$, we expect, based on the vast body of memory research linking exposure to a particular construct with the automatic activation of associated constructs (i.e., spreading activation; Collins and Loftus 1975) that the relative speed with which participants identify more emotional versus less emotional concepts will be greater after their 
exposure to information about the more emotional in-kind contributions relative to the less emotional monetary ones.

Design and Procedure

A total of 76 undergraduate students participated in this one between-subjects factor (Contribution type: Monetary vs. in-kind) study for partial course credit. As in study 1, participants read about an avalanche in California and a company's contribution to disaster relief. Unlike in study 1, however, the article explicitly stated that the cause of the disaster had not yet been determined (Gruman and Sloan 1983) to ensure that any differences in the emotion indices of participants were due only to differences in contribution type (i.e., not muddied by differences in perceived issue controllability). After describing the disaster, the article reported on a logistics company's disaster relief contribution to be either one million dollars that would be used for logistics support (i.e., monetary) or logistics services worth one million dollars (i.e., in-kind).

Next, participants engaged in a lexical decision task that was identical to that in study $2 \mathrm{~A}$ except for the inclusion, additionally, of the target word "effortful." This was included to examine empirically, given the findings of Ellen et al. (2000), the role of effort, if any, in the theorized difference in emotionality across the two contribution types. Upon finishing the lexical decision task, participants evaluated (7-point scales; $1=$ not at all, $7=$ very much) the company contribution on a series of dimensions: effortful, kind, humane, sincere, and helpful. Corporate responses considered more effortful, kind, and humane are perceived to be more heartfelt and thus produce more emotional reactions, particularly when perceived to be sincere (Morales 2005). Accordingly, we chose these items to gauge the different potential roles in the varying 
emotionality of the two contribution types, and thus averaged them to form a Contribution Beliefs index $(\alpha=.85)$.

Results and Discussion

The exclusion of participants who failed our general screening criteria as well as those who either incorrectly identified the target words or whose reaction times to these words were three standard deviations above the mean produced a final sample of 55 participants $(49.8 \%$ female; average age $=21.4$ ).

Emotion index. We performed the same analysis as in study 2A, using a Generalized Linear Model with gamma distribution and log link; results using linear regression were virtually identical. The model with Contribution Type predicting the emotion index revealed, as expected, a significant effect $\left(\beta=-.08, \chi^{2}=7.20, p<.01\right)$ such that participants in the in-kind contribution condition presented higher emotion index scores than those in the monetary contribution condition $\left(M_{\text {in-kind }}=584 ; M_{\text {monetary }}=200\right)$. In other words, as theorized, in-kind contributions appear to be associated with emotional concepts to a greater extent than are monetary contributions.

Other Measures. We ran an identical Generalized Linear Model with participants' reaction times to the word "effortful" as the dependent variable. Interestingly, the effect of Contribution Type was not significant $\left(\beta=-.16, \chi^{2}=1.81, p>.10\right)$. This suggests that the ascription of greater effort to a company's collection of products, versus cash, from its consumers (Ellen et al. 2000) may not necessarily generalize to a company's own in-kind, versus monetary, contributions, particularly when these are equivalent in overall value as in our studies. This was reflected, more generally, in the one-way ANOVA with Contribution Type predicting the 
Contribution Beliefs index, which revealed a directional but non-significant effect $\left(M_{\text {in-kind }}=\right.$ $\left.5.91, M_{\text {monetary }}=5.77, \mathrm{~F}(1,53)=.38, p>.10\right)$, due likely to the equivalence we imposed across the two contribution types in their overall value.

Taken together, then, studies $2 \mathrm{~A}$ and $2 \mathrm{~B}$ provide support for our theorizing regarding the greater emotionality of in-kind as opposed to monetary contributions, on the one hand, and consumers' greater intensity of felt emotions in response to CSR issues that are perceived to uncontrollable as opposed to controllable. Next, in study 3, we test for our assertion that consumers' differential reactions, in terms of company evaluations, to the lower emotionality monetary CSR contributions versus the higher emotionality in-kind contributions actually hinge on the greater levels of emotional intensity elicited by CSR issues that are perceived to be uncontrollable as opposed to controllable.

\section{STUDY 3}

This study had two objectives. The first objective was to test our theoretical assertion that controllability accessibility and perceived CSR issue controllability interact to determine the intensity of participants' felt emotion, which in turn interacts with CSR contribution types of varying emotionality to affect company evaluations. We did so by manipulating controllability accessibility, issue controllability, and contribution type, and measuring the intensity of participants' emotional reaction using an indirect task adapted from Quirin et al. (2009). We chose an indirect task to reduce concerns about social desirability (Quirin et al. 2009), as respondents could feel compelled, upon direct questioning, to indicate that they felt emotional after reading about a disaster. Our second objective was to enhance the generalizability of our 
findings by using alternative manipulations of controllability accessibility and issue controllability.

\section{Design and Procedure}

In line with its objectives, this study employed a 2 (Controllability Accessibility: high vs. low) $\times 2$ (Issue Controllability: high vs. low $) \times 2$ (Contribution Type: monetary vs. in-kind) between-subjects design. A total of 413 individuals based in the United States were recruited through Prolific Academic to participate in this study for a fee (17 participants who reported having technical issues received the fees but were not included in the sample). We increased our sample size in anticipation of a reduction in the effect size of the indirect effect (Cone and Ferguson 2015). Fifty-six participants (13.5\%) were excluded based on our screening criteria yielding a final sample of 357 participants $(40 \%$ female; average age $=33)$.

We first manipulated Controllability Accessibility by adapting a supraliminal priming procedure developed specifically to manipulate the accessibility of judgmental dimensions (Sherman et al. 1990). Specifically, we showed participants, in sequence, 10 pairs of words. In the case of each pair, a "memory" word (e.g., city, control) was presented on the left side of the screen and a "color" word (e.g., green, violet) was presented on the right side. In each word pair, the "memory" word was written in black on a white background, whereas the "color" word (e.g., orange) was presented in white on a colored background (e.g., blue) that was different, colorwise, from the "color" word it contained. For each pair, participants were asked to memorize the "memory" word presented on the left and the background color of the "color" word presented on the right. In the high Controllability Accessibility condition, four of the ten "memory" words were related to controllability (i.e., controllability, control, controlling, controlled) and the 
remaining six were neutral words. In the low Controllability Accessibility condition all ten "memory" words, including the four unique to this condition (i.e., computation, convenience, certification, city) were neutral. To avoid any potential confounds associated with the starting letter (i.e., "c") of the controllability-related words, all letters in both conditions started with a "c". For each word pair, participants were given five seconds to memorize the "memory" word and the background color and, after a 10 seconds pause during which they saw a blank screen, were instructed to type in the memorized word and color.

After completing the Controllability Accessibility manipulation, participants read the news report used to manipulate Issue Controllability. The report described a major flood that hit South Dakota in 2008 and stated that the disaster was either caused by ill constructed dams (i.e., high issue controllability) or by an unusually powerful storm (i.e., low issue controllability). This manipulation was underscored in the report through expert opinion that the dam had ruptured due to negligence (i.e., high issue controllability) versus a storm of historic proportions (i.e., low issue controllability). We checked the effectiveness of both the Controllability Accessibility and Issue Controllability manipulations through an online pretest $(\mathrm{N}=97)$ with the same Issue Controllability manipulation check measure $(r=.88, p<.001)$ and Victim Responsibility measure $(r=.79, p<.001)$ used in study 1 . Again, the effect of Issue Controllability on the manipulation check was significant $\left(M_{\text {high }}=5.77, M_{\text {low }}=2.67, \mathrm{~F}(1,93)=106.79, p<.001\right)$, as was the former's interactive effect with Controllability Accessibility $(\mathrm{F}(1,93)=5.11, p<.05)$. Planned contrast analysis revealed, as in study 1, a stronger effect of Issue Controllability in the high accessibility condition $\left(\mathrm{F}(1,94)=90.63, p<.001, \eta_{\mathrm{p}}^{2}=.49\right)$ than in the low accessibility one $\left(\mathrm{F}(1,93)=29.98, p<.001, \eta_{\mathrm{p}}^{2}=.24\right)$. The effect of Issue Controllability on Victim Responsibility was only marginally significant $\left(M_{\text {high }}=1.89, M_{\text {low }}=1.61, \mathrm{~F}(1,93)=2.86, p=\right.$ 
.09) denoting, again, a marginal role, if any, of victim responsibility attributions in participants' controllability perceptions.

After exposing participants to the news report, we assessed the intensity of their felt emotion using an indirect task to avoid potential demand effects (Quirin et al. 2009). Specifically, participants were asked to rate the extent to which they thought three artificial words (i.e., SAFME, TUNBA, and SUKOV) subjectively conveyed the mental states Emotional and Dull (1 $=$ Doesn't fit at all, $4=$ Fits very well). We chose these two mental states based on a recent study on the affective meaning of words (Warriner, Kuperman, and Brysbaert 2013), which shows that the word "Emotional" ["Dull"] rates significantly higher [lower] than the scale mean on the intensity (i.e., arousal) dimension of affective meaning, but not on either of the two other dimensions, valence and dominance. Because judgments about ambiguous objects such as artificial words are strongly influenced by one's affective state (Quirin et al. 2009), respondents experiencing greater emotional intensity should be more likely, compared to those experiencing lower emotional intensity, to ascribe the artificial words to an Emotional state as opposed to a Dull state. Accordingly, we created an Emotional Intensity index by averaging the scores for the mental state Dull ascribed to the three artificial words and subtracting it from the average score for the mental state Emotional (Quirin et al. 2009).

After completing the task, participants read one of the two news reports used in study 1 to manipulate Contribution Type and evaluated the company using study 1's measure $(\alpha=.90)$.

Results and Discussion

Company Evaluation. We tested our main outcome prediction using a 2 (Controllability Accessibility: high vs. low) $\times 2$ (Issue Controllability: high vs. low) $\times 2$ (Contribution Type: 
monetary vs. in-kind) ANOVA. As in study 1, the three-way interaction was significant ( $F(1$, $349)=5.87, p<.05)$. We also found a marginally significant Issue Controllability $\mathrm{x}$ Contribution Type interaction $(F(1,349)=3.31, p=.07)$. Most germane, the Issue Controllability $\mathrm{x}$ Contribution Type interaction was significant for participants in the high Controllability Accessibility condition $(F(1,354)=8.76, p<.01)$, but not for those in the low condition $(F<1)$. As predicted, participants in the high Controllability Accessibility condition evaluated the company more favorably when it made a monetary (versus in-kind) contribution to a controllable issue $\left(M_{\text {Monetary }}=6.03 ; M_{\text {In-kind }}=5.52, F(1,354)=4.40, p<.05\right)$, whereas the opposite was true when the issue was perceived as uncontrollable $\left(M_{\text {Monetary }}=6.11 ; M_{\text {In-kind }}=5.63, F(1,354)=\right.$ $4.36, p<.05)$. There were no differences in Company Evaluation for those in the low Controllability Accessibility condition $(F s<1)$.

Emotional Intensity. We tested for the effects of Controllability Accessibility and Issue Controllability on the Emotional Intensity index using an ANOVA. The main effects of Controllability Accessibility $(F(1,353)=2.82, p=.09)$ and Issue Controllability $(F(1,353)=$ 2.74, $p=.09$ ) were both marginally significant. More importantly, the two-way interaction was significant $(F(1,353)=5.18, p<.05)$. Contrast analyses supported our theorizing: participants in the high accessibility condition presented higher Emotional Intensity scores when the perceived issue controllability was low than when it was high $\left(M_{\text {low }}=.35 ; M_{\text {high }}=.05, F(1,354)=7.02, p<\right.$ $.01)$; those in the low accessibility condition displayed similar values of the Emotional Intensity index across the two level of Issue Controllability $\left(M_{\text {low }}=.05 ; M_{\text {high }}=.09, F<1\right)$.

To test for the driving role of emotional intensity in the contribution type-based differences in participants' company evaluations, we generated bootstrap confidence intervals (Hayes 2013) using the R software (R Development Core Team 2008) to capture the indirect 
effect of emotional intensity on company evaluations. In particular, we ran two regressions.

First, we regressed the Emotional Intensity index on Controllability Accessibility, Issue Controllability (both included as dummies) and their interaction. As in the case of the ANOVA, we obtained a significant interaction effect $(\beta=-.35, \mathrm{t}(353)=-2.28, p<.05)$. Second, we ran a regression that included all three manipulated factors (included as dummies), their two- and three-way interactions, along with the main effect of Emotional Intensity and its interaction with Contribution Type, as predictors of Company Evaluation. As expected, we found a significant Contribution Type $\times$ Emotional Intensity interaction $(\beta=-.32$, t $(353)=-2.05, p<.05)$. The main effect of Emotional Intensity $(\beta=.28, \mathrm{t}(353)=2.45, p<.05)$ and three-way interaction between the manipulated factors $(\beta=1.0, \mathrm{t}(353)=2.14, p<.05)$ were also significant. Finally, we generated 10,000 bootstraps to capture the indirect effect (path a = Controllability Accessibility $\times$ Issue Controllability $\rightarrow$ Emotional Intensity; path $b=$ Emotional Intensity $\times$ Contribution Type $\rightarrow$ Company Evaluation; Hayes 2013). Results revealed a significant indirect effect, as the 95\% confidence interval (CI) for the 10,000 bootstraps excluded zero $(\beta=.11, \mathrm{CI}$ : .01 to .26).

In sum, this study replicated our basic outcome finding (study 1) using a different manipulation of controllability accessibility and issue controllability. More importantly, this study provided evidence for the driving role of consumers' perceived CSR issue controllabilityinduced intensity of felt emotion in the interactive effect of controllability accessibility and issue controllability on consumers' evaluations of companies making monetary versus in-kind contributions. In the final study, described next, we test for the fluency-based contribution-cause fit component of our theoretical framework (see figure 1).

\section{STUDY 4}


This study had two objectives. First, we wanted to test for the theorized role of fluency in the interactive effect of CSR issue controllability and CSR contribution type on company evaluation through both mediation and moderation. To do so, we assessed the roles of participants' self-reported feelings of fluency while reading the news report about the CSR contribution and their perceptions of contribution-cause fit as sequential mediators of the interactive effect of contribution type and perceived issue controllability on company evaluations. As well, and in line with extant tests for fluency effects (Novemsky et al. 2007; Simmons and Nelson 2006; Topolinski and Strack 2009), we manipulated fluency independently of our focal manipulations to examine its moderation of the interactive effects of contribution type and issue controllability on participants' feelings of fluency, perceptions of contribution-cause fit, and company evaluations.

Second, we wanted to rule out an alternative explanation, based on victim deservingness, for our basic interaction. Specifically, since the victims of a controllable negative event or issue are more likely to be held responsible for their misfortunes, even when they actually played no part in causing it (results of study 1; Lerner 1980; Zagefka et al 2011), it is possible that consumers may deem them less deserving of a more emotional type of relief, evaluating the company making in-kind contributions less positively. This, possibly accompanied by consumers' more general affinity for in-kind help, and as well for the providing company, when the victims cannot be blamed (i.e., uncontrollable issue) could produce the pattern of company evaluations obtained in studies 1 and 3 .

Design and Procedure 
This study had a 2 (Contribution Type: Monetary vs. in-kind) $\times 2$ (Issue

Controllability: High vs. low) $\times 2$ (Fluency: Control condition vs. low fluency condition) between-subjects design. A total of 505 participants completed this study online in exchange for a fee. We increased our sample size in anticipation of the reduced effect sizes in the sequential mediation pathway (Cone and Ferguson 2015). The final sample, after excluding participants using our general screening criteria, was $431(41.7 \%$ female; average age $=32.7)$. While this exclusion rate (14.6\%) may seem somewhat high, it is on par with previous studies that used similar screening criteria and sampling frames (e.g., Baskin et al. 2014; Goodman, Cryder, and Cheema 2013).

We manipulated Issue Controllability as in study 3 by presenting participants with a news report describing a major flood that hit South Dakota in 2008. Since we were not interested in the moderating effect of controllability accessibility in this study, we modified the news report to systematically heighten the accessibility of the controllability dimension for all participants so as to ensure that the basic interaction between issue controllability and contribution type manifests. Specifically, we repeated the information pertaining to controllability (Lu et al. 2015; Feldman and Lynch 1988) multiple times throughout the news report, including the title as well as its final paragraph (see Zagefka et al. 2011 for a similar operationalization; materials available on web appendix).

Next, participants read a second news report containing the Contribution Type and Fluency manipulations. Contribution Type was identical to that in study $2 \mathrm{~B}$. The news report in the low Fluency condition was presented in embossed italicized gray font, which has been shown to be difficult to read and to, consequently, reduce processing fluency (Alter and Oppenheimer 2009; Novemsky et al. 2007; Oppenheimer and Frank 2008; Simmons and Nelson 2006). In 
contrast, the article in the control condition was presented using the standard font used in our previous studies.

After reading both news reports, participants evaluated the company using the same scale as in our previous studies $(\alpha=.94)$. Contribution-cause fit was measured with two items: "Does the type of aid provided by [the company] make sense?" and "Does the type of aid provided by [the company] feel right to you?" (7-point scale; $1=$ not at all, $7=$ a great deal). The two items, derived from existing measures of fluency-based judgments of fit (Hicks et al. 2010) were averaged to form a Fit index $(r=.80, p<.001)$. Feelings of Fluency were assessed through respondents' ratings of the news item containing the company's relief effort on two dimensions (7-point scales): 1 = very difficult to read $/$ unpleasant to read, $7=$ very easy to read $/$ pleasant to read (adapted from Song and Schwartz (2009), and Torelli and Ahluwalia (2012)). We averaged these two items to form a Feelings of Fluency index $(r=.58, p<.001)$.

We then checked the effectiveness of our Issue Controllability manipulation with the two items used in the study 1 pretest $(r=.92, p<.001)$. Next, participants indicated the extent to which they thought that the affected community was responsible for the disaster (using the same two items as in studies 1 and $3 ; r=.88, p<.001$ ), and the victims deserved the aid delivered by the company (7-point scale; 1 = totally disagree, 7 = totally agree; "The affected community deserves the aid delivered by [the company]"). As well, we assessed the extent to which the disaster scenarios triggered mortality salience to examine its potential effect if any; two items (7point scales; 1 = not at all, 7 = very much): "I think about how short life really is," and "I am very much afraid to die" were averaged to form a Mortality Salience index ( $r=.41, p<.001)$ (Ferraro, Shiv, and Bettman 2005). Finally, participants indicated the extent to which they thought that the 
news report about the corporate contribution was credible $(7$-point scale; $1=$ not at all, $7=a$ great deal), provided their demographic characteristics (i.e., gender, nationality, and age), and completed an attention check that asked them to indicate the cause of the disaster (ill constructed dam or historic flood) and the nature of the donation (monetary or services contribution).

Results and Discussion

An ANOVA with the three factors and their interactions as predictors of news report credibility revealed no significant main or interactive effects; the corporate contribution news report was perceived as equally credible across the two contribution types and fluency levels $\left(M_{\text {monetary-low fluency }}=5.42, M_{\text {monetary-control }}=5.55, M_{\text {service-low fluency }}=5.56, M_{\text {service-control }}=5.71, p\right.$ ' $s>$ $.10)$.

Manipulation and other checks. We ran an ANOVA with the three factors predicting our manipulation check for Issue Controllability. As expected, we found a strong main effect of Issue Controllability $\left(M_{\text {low controllability }}=2.55, M_{\text {high controllability }}=4.98 ; F(1,423)=225.65, p<.001\right) . \mathrm{We}$ also found an unexpected three-way interactive effect of Issue Controllability, Contribution Type, and Fluency $(F(1,423)=4.76, p<.05)$. However, the negligible effect size of the three-way interaction in comparison to the main effect of Issue Controllability indicated that the discriminant validity of Issue Controllability is not a concern $\left(\eta_{\mathrm{p}}^{2}\right.$ Issue Controllability $=.35 ; \eta_{\mathrm{p}}{ }^{2}$ Three-way Interaction $=.01 ;$ Perdue and Summers 1986).

We then checked for the aforementioned potential confounds using procedures outlined by Perdue and Summers (1986). An ANOVA with the three factors and their interactions predicting Mortality Salience revealed an unexpected main effect of Contribution Type ( $F$ (1, $423)=4.95, p<.05)$, but, importantly, no significant effect of Issue Controllability $(F(1,423)=$ 
$.35, p>.10)$. A similar ANOVA with Victim Responsibility as the dependent variable revealed, as in studies 1 and 3, only a significant main effect of Issue Controllability $\left(M_{\text {low }}\right.$ controllability $\left.=1.82, M_{\text {high controllability }}=2.54 ; F(1,423)=31.77, p<.001\right)$. However, effect size analyses corroborated the studies 1 and 3 findings regarding the far weaker variation in Victim Responsibility perceptions $\left(\eta_{\mathrm{p}}^{2}=.07\right)$ than in that attributed to someone (i.e., manipulation check; $\left.\eta_{\mathrm{p}}^{2}=.35\right)$. Finally, an ANOVA with perceptions of Victim Deservingness as the dependent variable revealed no significant effects $(p$ 's $>.10)$.

Company Evaluation. To test our main outcome prediction, we ran an ANOVA with Contribution Type, Issue Controllability, Fluency and all their interactions predicting Company Evaluation. We found a significant two-way interaction between Issue Controllability and Contribution Type $(F(1,423)=4.16, p<.05)$ as well as a marginally significant three-way interaction $(F(1,423)=3.01, p=.08)$. No other effects were significant. Consistent with our fluency account, planned simple two-way interaction analyses revealed that the interaction between Issue Controllability and Contribution Type was significant for participants exposed to the control condition $(F(1,428)=7.96, p<.01)$, but not for those exposed to the low fluency condition $(F(1,428)=.10, p>.10)$. As illustrated in Figure 3, planned simple main effect analyses revealed that, in the control condition, we replicated our basic study 1 and 3 result: the company was evaluated more favorably when it made an in-kind contribution, rather than an equivalent monetary one, to an uncontrollable disaster $\left(M_{\text {monetary }}=5.90, M_{\text {in-kind }}=6.28 ; F(1,426)\right.$ $=3.63, p=.05)$, whereas it was evaluated more favorably when it made a monetary contribution, rather than an equivalent in-kind one, to a controllable disaster $\left(M_{\text {monetary }}=6.37, M_{\text {in-kind }}=6.01 ; F\right.$ $(1,426)=4.38, p<.05)$. Importantly, however, and consistent with our fluency account, no 
contrasts were significant in the low fluency condition $\left(M_{\text {monetary-low controllability }}=5.98, M_{\text {in-kind-low }}\right.$ controllability $=6.16, M_{\text {monetary-high controllability }}=5.96, M_{\text {in-kind-high controllability }}=6.19 ; p$ 's $\left.>.10\right)$.

Insert Figure 3 about here

Feelings of Fluency. When Feelings of Fluency was analyzed using the same ANOVA, the three-way interaction was, as expected, significant $(F(1,423)=6.80, p<.01)$. Additionally, we found a significant main effect of Fluency $\left(M_{\text {control }}=5.83, M_{\text {low fluency }}=4.68 ; F(1,423)=\right.$ 76.61, $p<.01)$. Planned contrast analyses supported our fluency account: In the control condition, participants exposed to the uncontrollable disaster felt more fluency when reading about the in-kind contribution, as opposed to the monetary one $\left(M_{\text {monetary }}=5.58, M_{\text {in-kind }}=6.05 ; F\right.$ $(1,426)=4.22, p<.05)$, whereas those exposed to the controllable disaster felt more fluency reading about the monetary contribution, as opposed to the in-kind one $\left(M_{\text {monetary }}=5.94, M_{\text {in-kind }}=\right.$ $5.64 ; F(1,426)=3.33, p=.06)$. In contrast, there were no significant simple main effects in the low fluency condition $\left(M_{\text {monetary-low controllability }}=4.90, M_{\text {in-kind-low controllability }}=4.45, M_{\text {monetary-high }}\right.$ controllability $=4.62, M_{\text {in-kind-high controllability }}=4.75 ; p$ 's $\left.>.10\right)$.

Fit. We found a similar pattern of results using the identical ANOVA model with Fit as the dependent variable. Only the three-way interaction was significant $(F(1,423)=16.11, p<$ .001). Specifically, participants in the control condition perceived monetary, as opposed to inkind, contributions to be more fitting when the disaster was perceived to be controllable ( $M_{\text {monetary }}$ $\left.=6.28, M_{\text {in-kind }}=5.77 ; F(1,426)=8.22, p<.01\right)$, and in-kind (versus monetary) contributions to be more fitting when the disaster was perceived to be uncontrollable $\left(M_{\text {monetary }}=5.82, M_{\text {in-kind }}=\right.$ 
$6.29 ; F(1,426)=6.00, p<.01)$. Participants in the low fluency condition did not perceive any differences in fit across the monetary versus in-kind contribution conditions when exposed to the controllable disaster $\left(M_{\text {monetary }}=6.03, M_{\text {in-kind }}=6.04 ; F(1,426)=.00, p>.10\right)$. However, low fluency participants exposed to the uncontrollable disaster provided higher Fit ratings for monetary contributions than for in-kind ones $\left(M_{\text {monetary }}=6.26, M_{\text {in-kind }}=5.69, F(1,426)=7.82, p\right.$ $<.01)$. While unexpected, the potential meaningfulness of this pattern of means is undermined by its failure, unlike in the control condition, to manifest for the conceptually related Feelings of Fluency and Company Evaluation measures.

Mediation Analyses. To provide stronger support for our fluency-based account, we ran a mediated moderation analysis with two mediators modeled in a causal sequence (model 6; Hayes 2013). Specifically, the model included the three factors (coded as dummy variables), which, along with their interactions, predicted, in sequence, Feelings of Fluency, the perception of Fit, and Company Evaluation (Hayes 2013). As described above, the three-way interaction between Fluency, Contribution Type, and Issue Controllability was a significant predictor of Feelings of Fluency $(\beta=.1 .13, t(423)=2.22, p<.05)$. Further, after controlling for the main and interactive effects of our factors, Feelings of Fluency had a significant positive effect on Fit $(\beta=.23, t(423)$ $=6.76, p<.001)$. In the model predicting Company Evaluation, which included the main and interactive effects of the three manipulated factors as well as the main effects of both mediators, both Fit $(\beta=.69, t(423)=19.18, p<.001)$ and Feelings of Fluency $(\beta=.08, t(423)=3.08, p<$ .01) had significant positive effects. Importantly, the conditional indirect effect of the three-way interaction on Company Evaluation through, sequentially, Feelings of Fluency and Fit was, as expected, positive and significant (i.e., the 10,000 bootstraps 95\% confidence interval (CI) excluded zero; $\beta=.18, \mathrm{CI}: .03$ to .37 ), as was the indirect effect of the three-way interaction on 
Company Evaluation directly through Feelings of Fluency (i.e., portion of the indirect effect through Fluency that is not further mediated by Fit; $\beta=.09, \mathrm{CI}$ : .01 to .23 ). These results are consistent with our theorizing that Feelings of Fluency influence Company Evaluations both directly and indirectly, through perceptions of Fit. Finally, a mediation analysis pitting our proposed mediators against Victim Deservingness revealed a non-significant indirect effect through Victim Deservingness accompanied by no changes in the significant mediating effects of Fluency and Fit.

In sum, this study provided strong support for the fluency-based process theorized to underlie the interactive effect of CSR contribution type and perceived CSR issue controllability on consumers' company evaluations while ruling out certain key alternative accounts. One could argue, however, that our operationalization of low fluency through a difficult to read font lead participants to read the CSR contribution information less carefully, preventing, thus, our basic outcome prediction to manifest in the low fluency condition. However, two additional analyses invalidate this alternative attentional account. First, participants in the low fluency condition did not differ significantly from those in the control condition in their likelihood of correctly identifying the CSR contribution type: a binary logistic regression of error (i.e., dummy code indicating whether the contribution was identified incorrectly) on the three factors and their interaction indicated no-significant main and interactive effects $(p>.10)$. Second, and more importantly, we ran a posttest, with 94 online participants, in which we manipulated fluency (control condition vs. low fluency condition) and CSR contribution type (monetary vs. in-kind) as in the actual study, and measured (a) their accuracy in identifying the type of contribution (measured as in the actual study), (b) the attention they devoted to reading the information, assessed both objectively (time spent reading the report) and subjectively ("To what extent did 
you try hard to examine the information?", "How much effort did you put into examining the information?", "How much thought did you put into examining the information?", "How much attention did you pay to the information?", and "How involved were you in reading the task?"; 1 $=$ Not at all; $7=$ A great deal; Wheeler, Brinol, and Hermann 2007; $\alpha=.87$ ), and (c) their fluency in processing the information $(1=$ difficult to read; unpleasant to read; difficult to process; unpleasant to process; difficult to understand; unpleasant to understand; 7 = easy to read; pleasant to read; easy to process; pleasant to process; easy to understand; pleasant to understand; $\alpha=.91$ ). Results of the posttest indicated that participants differed, as predicted, in their perceived fluency $(\mathrm{F}(1,91)=23.18, p<.001)$ but did not differ in their attention to or comprehension of the information, in terms of both the objective and subjective assessments (Fs <1, $p$ 's >.10).

\section{GENERAL DISCUSSION}

Company support of CSR issues comes in many forms. Yet, we know little about the effects of varying contribution types on consumers' evaluations of the contributing company. Some research suggests that relative to monetary support, in-kind support can be viewed by consumers as more effortful and/or emotional (Ellen et al. 2000; Liu and Aaker 2008), pointing to the possibility that they might, in general, react more favorably to a company when it makes inkind as opposed to monetary contributions. Our research suggests that this evaluative advantage conferred by in-kind contributions actually hinges on characteristics of the contribution-eliciting CSR issue, such as its perceived controllability. Specifically, a company is evaluated more favorably when it makes in-kind rather than monetary contributions to issues that are perceived to be largely uncontrollable. However, in the case of issues perceived to be largely controllable, 
monetary contributions elicit more favorable company evaluations than do in-kind contributions of comparable magnitude. We also show that this interaction between contribution type and perceived issue controllability is more likely to manifest when controllability is accessible in the minds of consumers, and is driven by the extent to which the disparate emotionality of each contribution type matches intensity of the felt emotion evoked by CSR issues of varying perceived controllability. Together, these insights advance our conceptual understanding of not only consumer reactions to CSR and, more specifically, disaster relief, but also fluency. We discuss these next.

Theoretical Contributions

CSR. Our findings advance our conceptual sense for consumer reactions to CSR in three ways. First and most fundamentally, this paper is the first, to the best of our knowledge, to document the critical role played by consumers' perceptions of a CSR issue in their reactions to the type of contribution made by a company to that issue. This contrasts with the general dominance of in-kind contributions suggested by prior research (Ellen et al. 2000), and underscores the importance of the CSR context in consumers' appraisals of company involvement. As well, the moderation of our basic company evaluation interaction by the accessibility, either contextual or intrinsic, of controllability in the minds of consumers points to the importance of the precise nexus of consumer, CSR and company-specific factors in a meaningful understanding of consumer reactions to CSR.

Second, and more specifically, we add to the considerable work on the driving role of company/brand-CSR issue fit in consumer reactions to CSR (Ellen et al. 2006; Gupta and Pirsch 
2006; Kuo and Rice 2015; Nan and Heo 2007; Pracejus and Olsen 2004; Sen and Bhattacharya 2001). Widely acknowledged as a multidimensional construct (Zdravkovic, Magnusson, and Stanley 2010), fit, as examined thus far, refers broadly to the perceived match or closeness, in terms of image, positioning, and/or constituency (Varadarajan and Menon 1988), between a brand/company and the CSR issue(s) it supports. We build on this research by proffering a new dimension of fit, based on the characteristics of the contribution made by a company (as opposed to its more enduring dimensions such as its values) and the perceived controllability of the CSR issue (as opposed to its substantive domain). We also locate this contribution-cause fit in consumers' experience of processing fluency based on the congruence or match between the emotionality of the contribution type, on the one hand, and the intensity of the felt emotion engendered by the perceived controllability of the CSR issue, on the other. In this, we join more recent examinations of fit (e.g., perceptual fit based on matching colors, Kuo and Rice 2015) in broadening the bases of company-CSR issue fit beyond its traditional conceptualization based on the congruence between essentially conceptual dimensions (e.g., product category, target segment, brand image; Ellen et al. 2006; Sen, Bhattacharya, and Korschun 2006).

Third, and relatedly, while the vast majority of research in this domain has focused on the perceptual and cognitive mechanisms underlying consumer reactions to CSR (Sen et al. 2016), our research contributes to the more nascent stream of research focused on the more affective bases for such reactions. Specifically, researchers have recently implicated both moral emotions such as pride and guilt (Kim and Johnson 2013; Peloza et al. 2013) as well as feelings of empathy and gratitude (Xie, Bagozzi, and Grønhaug 2015) as drivers of consumers' reactions to CSR. Our research builds on this work to suggest, more generally, that the intensity of consumers' emotional reactions can also determine their CSR responses. 
Disaster relief. Based on its empirical context, this research also extends our understanding of consumer responses to, more specifically, disaster relief. Given that contributions to disaster relief are virtually de rigueur today for both global and local companies, a growing body of work examines global patterns in corporate disaster relief involvement (Gao 2011; Muller and Whiteman 2009; Patten 2008). However, our only understanding of consumer reactions to such corporate action comes, to the best of our knowledge, from Ellen et al. (2000)'s investigation of cause marketing in a retail setting: consumers are not only more likely to support a cause marketing program directed towards disaster relief as opposed to an ongoing issue, but also react more positively to a program that relies on in-kind contributions from a retailer's patrons, as opposed to monetary ones. Our research builds on this main effect finding by not only examining the extent to which it carries over to consumers' company evaluations but also, more vitally, fleshing out the disaster- (i.e., perceived controllability) and consumer-based (i.e., controllability accessibility) contingencies therein to paint a more comprehensive and nuanced picture of how consumers view corporate disaster relief efforts.

Viewed through the broader lens of prosocial behaviors in the context of disaster relief, our findings highlight some interesting differences between consumers' own charitable donations to disaster victims (Zagefka and James 2015) and their evaluations of companies doing the same. Specifically, prior research suggests that people are generally more likely to help victims of an uncontrollable misfortune than that of a controllable one (Weiner 1980; Weiner et al. 1988). This is consistent with the finding within the context of disaster relief (Zagefka et al. 2011) that disasters ascribed to natural causes elicit greater support than those ascribed to man-made causes. Our findings reveal, in contrast, that when consumers are observers rather than enactors of such helping behavior, there is no main effect of perceived controllability on judgments of the 
enactor's (i.e., the company) helping behavior. Instead, consumers' evaluations of the enactor hinge on the intensity of their disaster-induced felt emotions and its impact on their ease of processing subsequent contribution information. This difference is consistent, more broadly, with research on indirect reciprocity (i.e., when the observer rewards the enactor for helping a third party; Sigmund 2012) which suggests that the evaluation of a contribution from an enactor to a third party depends less on appraisals of the third party (e.g., victim responsibility) than on those of the enactor's actions (e.g., type of contribution).

Fluency. Finally, our findings contribute to the vast literature on processing fluency by implicating, for the first time, the intensity of an individual's felt emotions as yet another basis for their fluency experiences. In their integrative review of processing fluency, Alter and Oppenheimer (2009) present a wide array of known instantiations of fluency, stemming from a diversity of cognitive processes (Table 1; Alter and Oppenheimer 2009). Our findings regarding the driving role of consumers' perceived controllability-induced emotional intensity in their subsequent ease of processing contribution type information of varying emotionality and consequent company evaluations suggest that different emotional states can, like semantic, perceptual, and conceptual priming, comprise, in the words of Alter and Oppenheimer (2009), a fluency manipulation. At the same time, our findings complement that of Topolinski and Strack (2008, 2009) that a triad of words sharing an underlying semantic structure (e.g. foam, salt, and deep are all semantically linked to the sea) are more rapidly recognized, increasing feelings of fluency and perceptions of fit. Our research suggests that similarly intuitive judgments of fit may emerge for notions (e.g., issue controllability and contribution type) that share a commonality along the affective rather than semantic dimension. 
More specifically, in examining the role of emotional state-based fluency in consumers' CSR judgments, our research builds on extant CSR research focused on the driving role of conceptual fluency (e.g., that between the concept of CSR and varying brand concepts; Torelli, Monga, and Kaikati 2012) to broaden the scope of fluency processes in consumers' responses to CSR. We add to this nascent literature by demonstrating that fluency effects do not occur merely by increasing directly favorability of the fluently processed stimulus (e.g., CSR investment), but also indirectly, by increasing consumers' perception that the stimulus fits or is congruent with previously presented information (e.g., CSR issue). A systematic examination of the underlying roles of these as well as other, thus far unexamined bases for fluency in both judgments of company-CSR fit as well as their effects on CSR and company evaluations comprises an interesting future research direction. At the same time, the relative role of such fluency processes in driving consumer preferences for company actions in domains beyond CSR (e.g., brand failures; Smith Bolton and Wagner 1999) demands further investigation.

\section{Limitations and Future Research}

Naturally, this research has certain limitations, which point to directions for future research. We test our framework exclusively in the context of disaster relief. While the type of fit proffered by our research can, importantly, be expected to generalize to any CSR issue wherein controllability looms large in consumers' minds, empirical corroboration is an essential next step. Future research might also want to consider assessing whether and the extent to which the match between the perceived controllability of a CSR issue (e.g., breast cancer) and its specific 
implementation (e.g., Avon’s Breast Cancer Walk versus Mary Kay’s monetary donations for cancer research) influences consumer reactions towards the CSR initiative and the company.

In a similar vein, all our studies focused on the role of perceived CSR issue controllability in determining the intensity of consumers' felt emotions. It is entirely conceivable, however, that this intensity may also be amplified or reduced by other dimensions of the CSR issue such as the issue beneficiary's physical or temporal closeness to the consumer (Loewenstein and Small 2007; Trope and Liberman 2010), the inability of the beneficiary to exert intentional control over his or her actions (e.g., children, mentally ill individuals; Malle, Guglielmo, and Monroe 2014), or the beneficiary's similarity with consumers (Loewenstein and Small 2007). While we took care to control for such potentially confounding differences, it would be interesting for future research to investigate whether the contribution type-triggered differences in company evaluations obtained in our research could be produced through CSR issues that vary in these characteristics.

Additionally, in our research the company contributing to the CSR issue was not in any way responsible for causing or exacerbating the issue. It is possible, particularly in today's marketplace, that the companies helping to ameliorate a CSR issue may be the ones responsible for the issue in the first place (e.g., BP compensatory efforts after the Gulf of Mexico oil spill, and more generally, the "green" efforts of companies that have contributed significantly to the degradation of the environment). Clearly, company culpability in the CSR issue is likely to alter the dynamics documented by our paper. For instance, consumers may expect the offending company to go beyond monetary contributions and be intimately and comprehensively involved in relief efforts even though, and in fact because, the disaster is deemed as controllable. Interestingly, some research (Muller and Whiteman 2009) suggests that stakeholders may have similar expectations of companies that are merely physically closer to the disaster, even in the 
absence of culpability. It would be important for future research to investigate consumer responses to remedial rather than prosocial CSR actions taken by a company.

Finally and more specifically, research (Liu et al. 2012) points to the importance of businesses in helping victims of disasters regain their lives and, through that process, their very identities. The roles of perceived disaster controllability and company involvement, and indeed other key disaster- and company-related factors in this profoundly important process would comprise a worthwhile research endeavor. 
Data Collection Information

The first two authors collected the data either at Baruch College/CUNY or online using the panel Amazon Mechanical Turk and Prolific Academic, as well as analyzed these data. They collected data for study 1 in Winter 2014 (online), study 2a in Fall 2010, study 2b in Spring 2014, study 3 in Fall 2016 (online), and study 4 in Spring 2015 (online). 


\section{REFERENCES}

Alicke, Mark D. (2000), “Culpable Control and the Psychology of Blame,” Psychological Bulletin, 126 (4), 556-74.

Alter, Adam L., and Daniel M. Oppenheimer (2009). "Uniting the Tribes of Fluency to Form a Metacognitive Nation,” Personality and Social Psychology Review, 13, 219-35.

Bar-Anan, Yoav, Timothy D. Wilson, and Daniel T. Gilbert (2009), "The Feeling of Uncertainty Intensifies Affective Reactions," Emotion, 9 (1), 123-7.

Baskin, Ernest, Cheryl J. Wakslak, Yaacov Trope, and Nathan Novemsky (2014), "Why Feasibility Matters More to Gift Receivers than to Givers: A Construal-Level Approach to Gift Giving," Journal of Consumer Research, 41 (1), 169-82.

Baum, Andrew, and India Fleming (1993), "Implications of Psychological Research on Stress and Technological Accidents," American Psychologist, 48 (6), 665-72.

Bhatia, Sudeep (2013), “Associations and the Accumulation of Preference,” Psychological Review, 120 (3), 522-43.

Bin, Okmyung, and Bob Edwards (2009), "Social Capital and Business Giving to Charity Following a Natural Disaster: An Empirical Assessment,” Journal of Socio-Economics, $38,601-7$.

Bohner, Gerd, Herbert Bless, Norbert Schwarz, and Fritz Strack (1988), "What Triggers Causal Attributions? The Impact of Valence and Subjective Probability," European Journal of Social Psychology, 18, 335-45.

Brosch, Tobias, Gilles Pourtois and David Sander (2010), “The Perception and Categorization of Emotional Stimuli: A Review," Cognition \& Emotion, 24 (3), 377-400. 
Burger, Jerry M., and Robert M. Arkin (1980), "Prediction, Control, and Learned

Helplessness," Journal of Personality and Social Psychology, 38 (3), 482-91. , and Harris M. Cooper (1979), “The Desirability of Control, "Motivation and Emotion, 3 (4), 381-93. , and Lawton T. Hemans (1988), "Desire for Control and the Use of Attribution Processes," Journal of Personality, 56 (3), 531-46.

Cervone, Daniel, Tracy L. Caldwell, Marina Fiori, Heather Orom, William G. Shadel, Jon D. Kassel, and Daniele Artistico (2008), "What Underlies Appraisals? Experimentally Testing a Knowledge-and-Appraisal Model of Personality Architecture Among Smokers Contemplating High-Risk Situations," Journal of Personality, 76 (4), 929-68.

Chatterjee, Promothesh, Caglar Irmak, and Randall L. Rose (2013), "The Endowment Effect as Self-Enhancement in Response to Threat," Journal of Consumer Research, 40 (3), 46076.

Collins, Allan M., and Elizabeth F. Loftus (1975), "A Spreading-Activation Theory of Semantic Processing," Psychological Review, 82 (6), 407-28.

Cone, Jeremy, and Melissa J. Ferguson (2015), "He Did What? The Role of Diagnosticity in Revising Implicit Evaluations," Journal of Personality and Social Psychology, 108 (1), $37-57$.

Dou, Eva, and Chun Wan Wong (2015), “Landslide Lays Bare Shenzhen’s Contrasts,” Wall Street Journal, December 25, http://www.wsj.com/articles/landslide-lays-bare-shenzhenscontrasts-1451090631.

Dweck, Carol S., Mangels, Jennifer A., and Good, Catherine (2004), "Motivational Effects on Attention, Cognition, and Performance," in Motivation, Emotion, and Cognition: 
Integrative Perspectives on Intellectual Functioning and Development, ed. David Yun

Dai and Robert J. Sternberg, 41-56, Mahwah, NJ: Lawrence Erlbaum.

Ellen, Pam Scholder, Lois A. Mohr, and Deborah J. Webb (2000), "Charitable Programs and the Retailer: Do They Mix?” Journal of Retailing, 76 (3), 393-406.

, Deborah J. Webb, and Lois A. Mohr (2006), "Building Corporate Associations: Consumer Attributions for Corporate Socially Responsible Programs," Journal of Academy of Marketing Science, 34 (2), 147-57.

Ellingsen, Tore, and Magnus Johannesson (2011), “Conspicuous Generosity,” Journal of Public Economics, 95 (9-10), 1131-43.

Fazio, Russell H. (1990), “A Practical Guide to the Use of Response Latencies in Social Psychological Research," in Review of Personality and Social Psychology, ed. Clyde A. Hendrick and Margaret S. Clark, Newbury Park, CA: Sage, 74-97.

Feldman, Jack M., and John G. Lynch Jr. (1988), "Self-Generated Validity and Other Effects of Measurement on Belief, Attitude, Intention, and Behavior," Journal of Applied Psychology, 73 (3), 421-35.

Ferraro, Rosellina, Baba Shiv, and James R. Bettman (2005), "Let Us Eat and Drink, for Tomorrow We Shall Die: Effects of Mortality Salience and Self-Esteem on SelfRegulation in Consumer Choice," Journal of Consumer Research, 32 (June), 65-75.

Förster, Jens, and Nira Liberman (2007), "Knowledge Activation," in Social Psychology:

Handbook of Basic Principles, ed. E. Tory Higgins and Arie W. Kruglanski, New York: Guilford Press, 201-31.

Gao, Yongqiang (2011), "Philanthropic Disaster Relief Giving as a Response to Institutional Pressure: Evidence from China," Journal of Business Research, 64 (12), 1377-82. 
Gino, Francesca, and Francis J. Flynn (2011), "Give Them What They Want: The Benefits of Explicitness in Gift Exchange," Journal of Experimental Social Psychology, 47, 915-22.

Goodman, Joseph K., Cynthia E. Cryder, and Amar Cheema (2013), "Data Collection in a Flat World: The Strengths and Weaknesses of Mechanical Turk Samples," Journal of Behavioral Decision Making, 26 (3), 213-24.

Gruman, Jessie C., and Richard P. Sloan (1983), "Disease as Justice: Perceptions of the Victims of Physical Illness," Basic and Applied Social Psychology, 4 (1), 39-46.

Gupta, Shruti, and Julie Pirsch (2006), “The Company-Cause-Customer Fit Decision in CauseRelated Marketing," Journal of Consumer Marketing, 23 (6), 314-26.

Halberstadt, Jamin Brett, and Paula M. Niedenthal (1997), "Emotional State and the Use of Stimulus Dimensions in Judgment," Journal of Personality and Social Psychology, 72 (5), 1017-33.

Harris, Peter R., Dale W. Griffin, and Sandra Murray (2008), “Testing the limits of optimistic bias: Event and person moderators in a multilevel framework," Journal of Personality and Social Psychology, 95 (5), 1225 - 1237

Hayes, Andrew F. (2013), Introduction to Mediation, Moderation, and Conditional Process Analysis: A Regression-Based Approach, New York, NY: The Guilford Press.

Hicks, Joshua A., David C. Cicero, Jason Trent, Chad M. Burton, and Laura A. King (2010), "Positive Affect, Intuition, and Feelings of Meaning," Journal of Personality and Social psychology, 98 (6), 967-79.

Higgins, Edward T. (1996), "Knowledge Activation: Accessibility, Applicability, and Salience," in Social Psychology: Handbook of Basic Principles, ed. E. Tory Higgins and Arie W. Kruglanski, New York: Guilford Press, 133-68. 
Hsee, Christopher K., and Yuval Rottenstreich (2004), "Music, Pandas and Muggers: On the Affective Psychology of Value,” Journal of Experimental Psychology: General, 133 (1), 23-30.

Huffington Post (2013), “People With Controlled HIV Don’t Have Higher Death Risk, Study Finds," Huffington Post, March 12, http://www.huffingtonpost.com/2013/03/12/ controlled-hiv-death-risk-antiretroviral-medications-drugs_n_2862627.html. Jacobsson, Fredric, Magnus Johannesson, and Lars Borgquist (2007), “Is Altruism Paternalistic?" The Economic Journal, 117 (520), 761-81.

Kim, Jae-Eun, and Kim K. P. Johnson (2013), “The Impact of Moral Emotions on Cause-Related Marketing Campaigns: A Cross-Cultural Examination,” Journal of Business Ethics, 112 (1), 79-90.

Kim, Junsuk, Johannes Schultz, Tim Rohe, Christian Wallraven, Seong-Whan Lee, and Heinrich H. Bülthoff (2015), "Abstract Representations of Associated Emotions in the Human Brain,” Journal of Neuroscience, 35 (14), 5655-63.

Kolata, Gina (2015), “A Years Later, No Magic Bullet Against Alzheimer's Disease,” The New York Times, August 28, http://www.nytimes.com/2010/08/29/health/research/ 29prevent.html.

Kuo, Andrew, and Dan Hamilton Rice (2015), "The Impact of Perceptual Congruence on the Effectiveness of Cause-related Marketing Campaigns," Journal of Consumer Psychology, 25 (1), 78-88.

Lai, Vicky Tzuyin, Peter Hagoort, and Daniel Casasanto (2012), “Affective Primacy vs. Cognitive Primacy: Dissolving the Debate," Frontiers in Psychology, 3, 1-8. 
Lakens, Daniel (2011), "Polarity Correspondence in Metaphor Congruency Effects: Structural Overlap Predicts Categorization Times for Bipolar Concepts Presented in Vertical Space,” Journal of Experimental Psychology: Learning, Memory, and Cognition, 38 (3), 726-36.

Lerner, Melvin J. (1980), The Belief in a Just World, Springer US.

Levine, Susan C., and Gerardo Ramirez (2013), “An Attentional Theory of Emotional Influences on Risky Decisions," Progress in Brain Research, 202, 369-88.

Liu, Chuanlan, William C. Black, Frances C. Lawrence, and M.E. Betsy Garrison (2012), “PostDisaster Coping and Recovery: The Role of Perceived Changes in the Retail Facilities," Journal of Business Research, 65 (5), 641-47.

Liu, Wendy, and Jennifer Aaker (2008), “The Happiness of Giving: The Time-Ask Effect,” Journal of Consumer Research, 35 (October), 543-57.

Lo, Steson, and Sally Andrews (2015), “To Transform or Not to Transform: Using Generalized Linear Mixed Models to Analyse Reaction Time Data," Frontiers in Psychology, 6, 1-16. Loewenstein, George, and Deborah A. Small (2007), "The Scarecrow and the Tin Man: The Vicissitudes of Human Sympathy and Caring," Review of General Psychology, 11 (2), $112-26$.

Lu, Xi, Xiaofei Xie, and Lu Liu (2015), "Inverted U-shaped Model: How Frequent Repetition Affects Perceived Risk," Judgment and Decision Making, 10 (23), 219-24.

Malle, Bertram F., Steve Guglielmo, and Andrew E. Monroe (2014), "A Theory of Blame,” Psychological Inquiry, 25, 147-186.

McCutcheon, Lynn E. (2000), “The Desirability of Control Scale: Still Reliable and Valid Twenty Years Later," Current Research in Social Psychology, 5 (15), 225-35.

Morales, Andrea C. (2005), "Giving Firms an "E” for Effort: Consumer Responses to High Effort 
Firms," Journal of Consumer Research, 31 (March), 806-12.

Muller, Alan and Gail Whiteman (2009), "Exploring the Geography of Corporate Philanthropic Disaster Response: A Study of Fortune Global 500 Firms,” Journal of Business Ethics, 84 (4), 589-603.

Mussweiler, Thomas, and Lysann Damisch (2008), "Going Back to Donald: How Comparisons Shape Judgmental Priming Effects, ” Journal of Personality and Social Psychology, 95 (6), 1295-315.

Nan, Xiaoli and Kwangjun Heo (2007), "Consumer Responses to Corporate Social Responsibility (CSR) Initiatives: Examining the Role of Brand-Cause Fit in Cause-Related Marketing," Journal of Advertising, 36 (Summer), 63-74.

Niedenthal, Paula M., Jamin B. Halberstadt, and Åse H. Innes-Ker (1999), "Emotional Response Categorization," Psychological Review, 106 (2), 337-61.

Nielsen, Jesper H., Stewart A. Shapiro, Charlotte H. Mason (2010), "Emotionality and Semantic Onsets: Exploring Orienting Attention Responses in Advertising," Journal of Marketing Research, 47 (6), 1138-50.

Novemsky, Nathan, Ravi Dhar, Norbert Schwarz, and Itamar Simonson (2007), "Preference Fluency in Choice," Journal of Marketing Research, 44 (3), 347-56.

Patten, Dennis M. (2008), "Does the Market Value Corporate Philanthropy? Evidence from the Response to the 2004 Tsunami Relief Effort," Journal of Business Ethics, 81 (3), 599607.

Peloza, John, Katherine White, and Jingzhi Shang (2013), “Good and Guilt-Free: The Role of Self-Accountability in Influencing Preferences for Products with Ethical Attributes," Journal of Marketing, 77 (1), 104-19. 
Perdue, Barbara C., and John O. Summers (1986), "Checking the Success of Manipulations in Marketing Experiments," Journal of Marketing Research, 23 (4), 317-26.

Pfeffer, Jeffery, and Sanford E. DeVoe (2009), "Economic Evaluation: The Effect of Money and Economics on Attitudes about Volunteering," Journal of Economic Psychology, 30 (3), $500-8$

Pieters, Rik, and Henry Robben (1999), "Consumer Evaluation of Money as a Gift: A TwoUtility Model and an Empirical Test," Kyklos: International Review for Social Sciences, $52(2), 173-200$.

Pracejus, John W., and G. Douglas Olsen (2004), “The Role of Brand/Cause Fit in the Effectiveness of Cause-Related Marketing Campaigns," Journal of Business Research, $57,635-40$.

Quirin, Markus, Miguel Kazén, and Julius Kuhl (2009), “When Nonsense Sounds Happy or Helpless: The Implicit Positive and Negative Affect Test (IPANAT)," Journal of Personality and Social Psychology, 97 (3), 500-16.

Quoidbach, Jordi, Elizabeth W. Dunn, K. V. Petrides, and Moira Mikolajczak (2010), "Money Giveth, Money Taketh Away: The Dual Effect of Wealth on Happiness," Psychological Science, 21(6), 759-63.

R Development Core Team (2008). R: A Language and Environment for Statistical Computing. $R$ Foundation for Statistical Computing, Vienna, Austria.

Reed, Americus II, Karl Aquino, and Eric Levy (2007), “Moral Identity and Judgments of Charitable Behaviors," Journal of Marketing, 71 (1), 178-93.

Robben, Henry S. J., and T. M. M. Verhallen (1994), "Behavioral Costs as Determinants of Cost 
Perception and Preference Formation for Gifts to Receive and Gifts to Give," Journal of Economic Psychology, 15 (2), 333-50.

Schul, Yaacov, Ruth Mayo, Eugene Burnstein, and Naomi Yahalom (2007), How People Cope with Uncertainty Due to Chance or Deception, Journal of Experimental Social Psychology, 43, 91-103.

Schwarz, Norbert, and Gerald L. Clore (1996), "Feelings and Phenomenal Experiences," in Social Psychology: Handbook of Basic Principles, ed. E. Tory Higgins and Arie W. Kruglanski, New York: Guilford, 433-65.

Sen, Sankar and C. B. Bhattacharya (2001), "Does Doing Good Always Lead to Doing Better? Consumer Reactions to Corporate Social Responsibility," Journal of Marketing Research, $38(2), 225-43$.

, C. B. Bhattacharya, and Daniel Korschun (2006), "The Role of Corporate Social Responsibility in Strengthening Multiple Stakeholder Relationships: A Field Experiment," Journal of the Academy of Marketing Science, 34 (2), 158-66. , Shuili Du and CB Bhattacharya (2016). "Corporate Social Responsibility: A Consumer Psychology Perspective," Current Opinion in Psychology, 10, 70-75

Shapiro, Stewart (1999), “When an Ad's Influence is Beyond our Conscious Control: Perceptual and Conceptual Fluency Effects Caused by Incidental Ad Exposure,” Journal of Consumer Research, 26 (1), 16-36.

Sherman, Steven J., Diane M. Mackie, and Denise M. Driscoll (1990), "Priming and the Differential Use of Dimensions in Evaluation," Personality and Social Psychology Bulletin, 16 (3), 405-18. 
Sigmund, Karl (2012), "Moral Assessment in Indirect Reciprocity,” Journal of Theoretical Biology, 299, 25-30.

Simmons, Joseph P., and Leif D. Nelson (2006), "Intuitive Confidence: Choosing between Intuitive and Nonintuitive Alternatives," Journal of Experimental Psychology: General 135(3), 409-28.

Smith, Amy K., Ruth N. Bolton, and Janet Wagner (1999), “A Model of Customer Satisfaction with Service Encounters Involving Failure and Recovery,” Journal of Marketing Research, 36 (3), 356-72.

Smith, Craig A., Kelly N. Haynes, Richard S. Lazarus, and Lois K. Pope (1993), "In Search of the" Hot" Cognitions: Attributions, Appraisals, and their Relation to Emotion," Journal of Personality and Social Psychology, 65 (5), 916-29.

Smith, Eliot R., and Nyla R. Branscombe (1987), "Procedurally Mediated Social Inferences: The Case of Category Accessibility Effects," Journal of Experimental Social Psychology, 23 (5), 361-82.

Song, Hyunjin, and Norbert Schwarz (2009), "If It's Difficult to Pronounce, It Must Be Risky Fluency, Familiarity, and Risk Perception,” Psychological Science, 20 (2), 135-38.

Taylor, Shelley E., and Susan T. Fiske (1978), "Salience, Attention, and Attribution: Top of the Head Phenomena," Advances in Experimental Social Psychology, 11, 249-88.

Thompson, Suzanne C. and Michele Schlehofer (2008), "Control, Denial, and Heightened Sensitivity Reactions to Personal Threat: Testing the Generalizability of the Threat Orientation Approach,” Personality Social Psychology Bulletin, 34 (8), 1070-83.

Torelli, Carlos J., and Rohini Ahluwalia (2012), "Extending Culturally Symbolic Brands: A Blessing or a Curse?" Journal of Consumer Research, 38 (February), 933-47. 
, Alokparna Basu Monga, and Andrew M. Kaikati (2012), "Doing Poorly by Doing Good: Corporate Social Responsibility and Brand Concepts,” Journal of Consumer Research, 38 (February), 948-63.

Topolinski, Sascha, and Fritz Strack (2008), "Where There's a Will-There's no Intuition. The Unintentional Basis of Semantic Coherence Judgments," Journal of Memory and Language, 58 (4), 1032-48. , and ___ (2009), “The Architecture of Intuition: Fluency and Affect Determine Intuitive Judgments of Semantic and Visual Coherence and Judgments of Grammaticality in Artificial Grammar Learning,” Journal of Experimental Psychology: General, 138 (1), $39-63$.

Trope, Yaacov, and Nira Liberman (2010), "Construal-Level Theory of Psychological Distance," Psychological Review, 117 (2), 440-63.

U.S. Chamber of Commerce (2011), “Corporate Aid Trackers,” www.uschanberfoundation.org/corporate-citizenship-center/corporate-aid-trackers.

Van Boven, Leaf, and Thomas Gilovich (2003), "To Do or To Have? That is the Question," Journal of Personality and Social Psychology, 85, 1193-202.

Varadarajan, P. Rajan and Anil Menon (1988), “Cause Related Marketing: A Co-Alignment of Marketing Strategy and Corporate Philanthropy,” Journal of Marketing, 52 (3), 58-74.

Vohs, Kathleen D., Nicole L. Mead, and Miranda R. Goode (2006), “The Psychological Consequences of Money," Science, 314, 1154-56.

Warriner, Amy Beth, Victor Kuperman, and Marc Brysbaert (2013), 'Norms of Valence, Arousal, and Dominance for 13,915 English Lemmas," Behavior Research Methods, 45 (4), 1191-1207. 
Webley, Paul, Stephen EG Lea, and Renata Portalska (1983), "The Unacceptability of Money as a Gift," Journal of Economic Psychology, 4 (3), 223-38.

Weiner, Bernard (1980), “A Cognitive (Attribution)-Emotion-Action Model of Motivated Behavior: An Analysis of Judgments of Help Giving," Journal of Personality and Social Psychology, 39 (2), 186-200.

, Raymond P. Perry, and Jamie Magnusson (1988), “An Attributional Analysis of Reactions to Stigmas," Journal of Personality and Social Psychology, 55 (5), 738-48.

, Danny Osborne, and Udo Rudolph (2011), “An Attributional Analysis of Reactions to Poverty: The Political Ideology of the Giver and the Perceived Morality of the Receiver," Personality and Social Psychology Review, 15 (2), 199-213.

Wheeler, S. Christian, Pablo Brinol, and Anthony D. Hermann (2007), "Resistance to Persuasion as Self-Regulation: Ego-Depletion and its Effects on Attitude Change Processes,” Journal of Experimental Social Psychology, 43 (1), 150-56.

Wilcox, Keith, Beth Vallen, Lauren Block, and Gavan J. Fitzsimons (2009), "Vicarious Goal Fulfillment: When the Mere Presence of a Healthy Option Leads to an Ironically Indulgent Decision," Journal of Consumer Research, 36 (3), 380-93.

Wilson, Timothy, D. and Daniel T. Gilbert (2003), “Affective Forecasting," Advances In Experimental Social Psychology, 35, 345-411.

Xie, Chunyan, Richard P. Bagozzi, and Kjell Grønhaug (2015), “The Role of Moral Emotions and Individual Differences in Consumer Responses to Corporate Green and Non-green Actions," Journal of the Academy of Marketing Science, 43 (3), 333-56. 
Yoon, Yeosun, and Zeynep Gürhan-Canli, and Norbert Schwarz (2006), "The Effect of Corporate Social Responsibility (CSR) Activities on Companies with Bad Reputations," Journal of Consumer Psychology, 16 (4), 377-90.

Zagefka, Hanna, and Trevor James (2015), “The Psychology of Charitable Donations to Disaster Victims and Beyond," Social Issues and Policy Review, 9 (1), 155-92.

, Masi Noor, Ruper Brown, Georgina R. de Moura, and Tim Hopthrow (2011), "Donating to Disaster Victims: Responses to Natural and Humanity Caused Events,” European Journal of Social Psychology, 41 (3), 353-63.

Zdravkovic, Srdan, Peter Magnusson, and Sarah M. Stanley (2010), "Dimensions of Fit between a Brand and a Social Cause and their Influence on Attitudes," International Journal of Research in Marketing, 27 (2), 151-60. 
FIGURE 1: Conceptual Framework

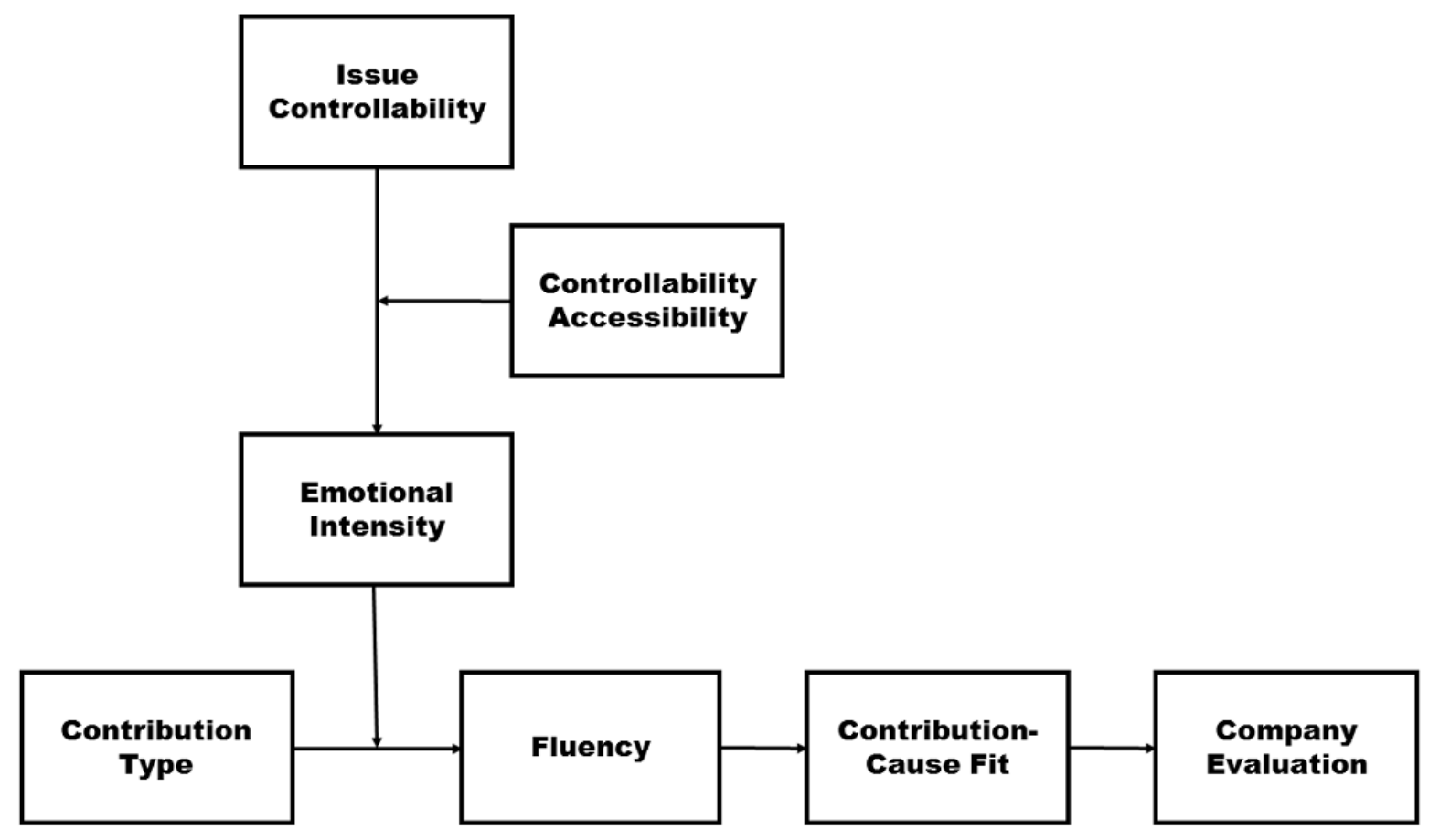


FIGURE 2: Effect of Issue Controllability, Controllability Accessibility, and Contribution Type on Company Evaluation (Study 1)

A: High Controllability Accessibility condition

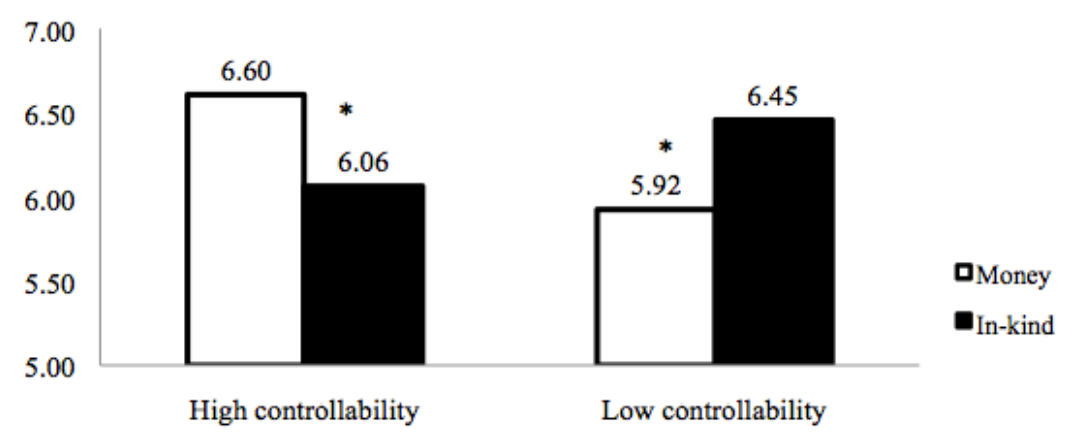

B: Low Controllability Accessibility condition

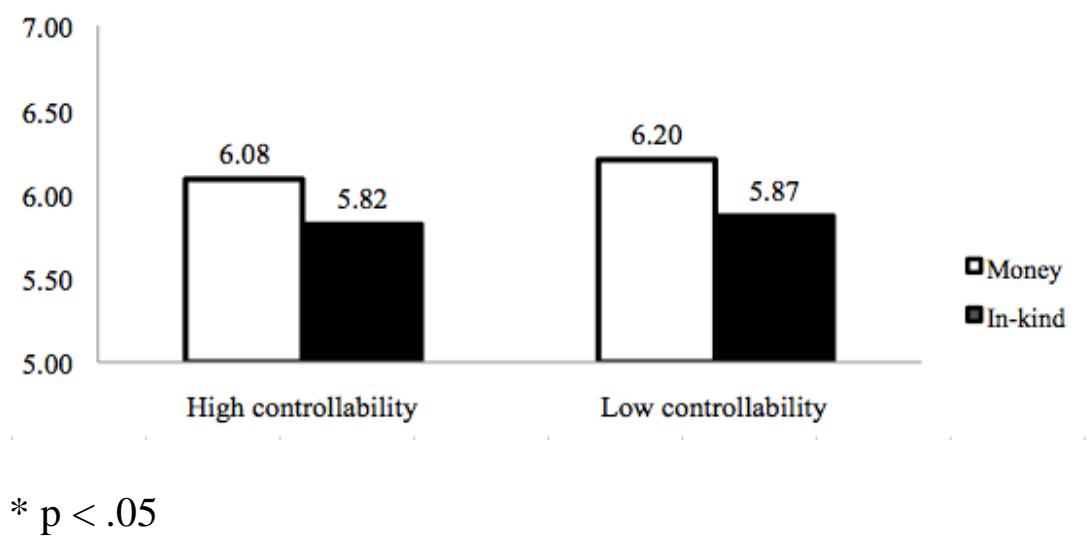


FIGURE 3: Effect of Issue Controllability, Contribution Type, and Processing Fluency on

Company Evaluation (Study 4)

A: Control condition

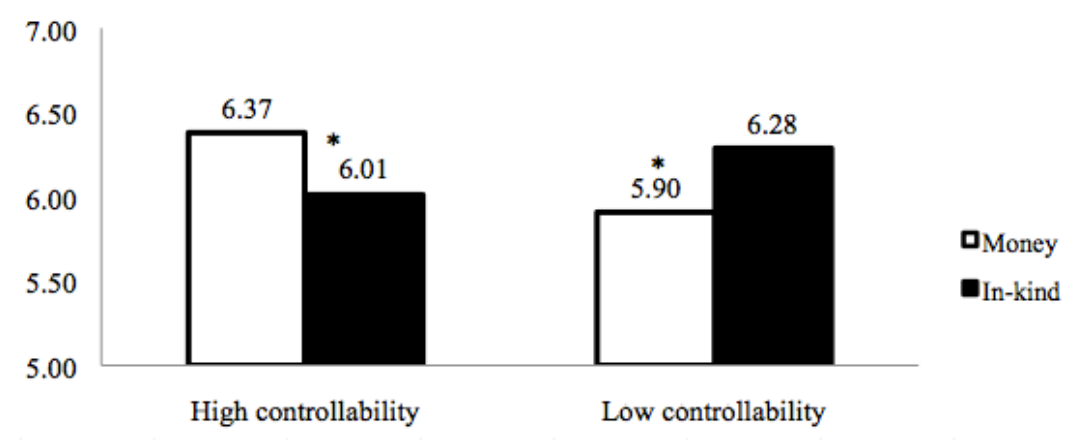

B: Low Fluency condition

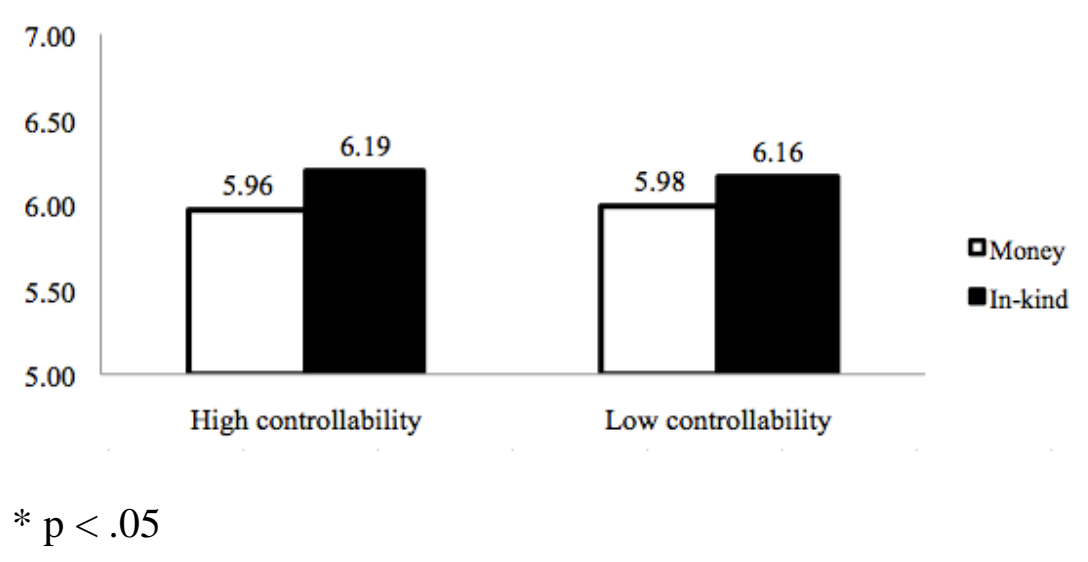

